\title{
Interindividual Differences in Caffeine Metabolism and Factors Driving Caffeine Consumption
}

\author{
Astrid Nehlig
}

INSERM U 1129, Pediatric Neurology, Necker-Enfants Malades Hospital, University of Paris Descartes, Inserm U1129, Paris, France

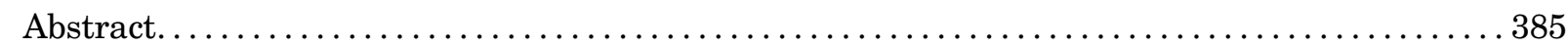

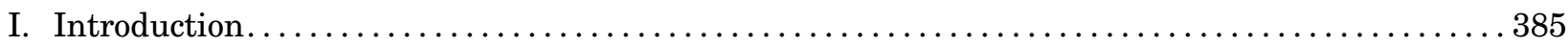

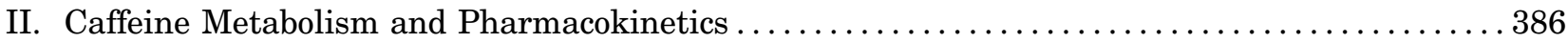

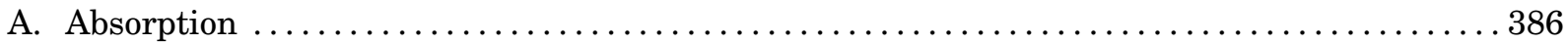

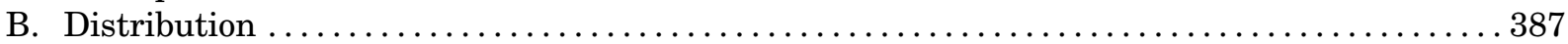

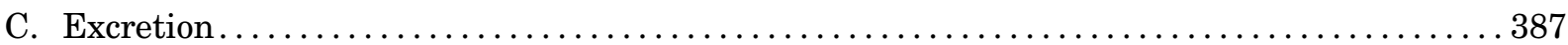

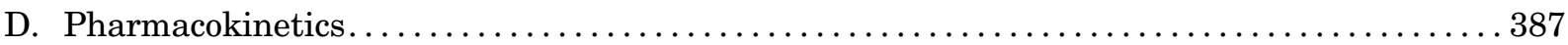

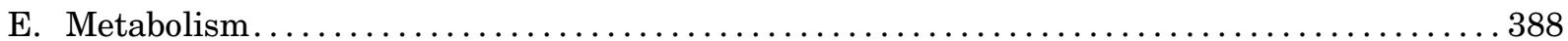

III. Effect of Various Factors on Caffeine Metabolism $\ldots \ldots \ldots \ldots \ldots \ldots \ldots \ldots \ldots$

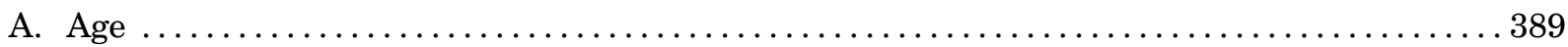

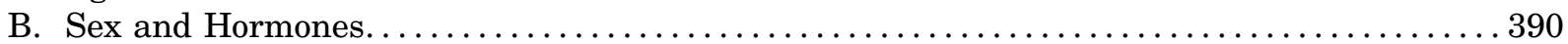

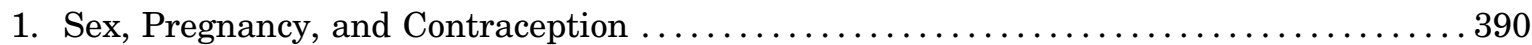

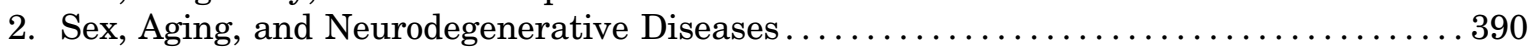

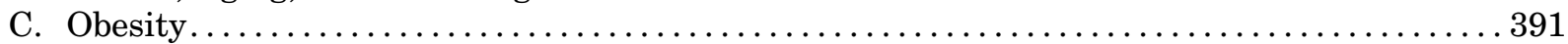

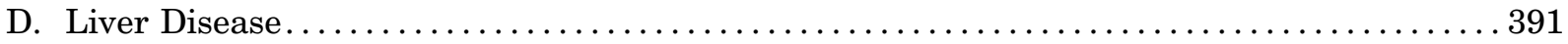

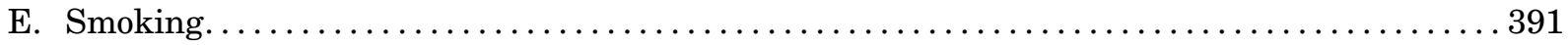

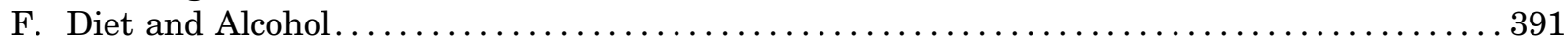

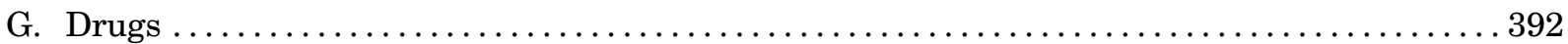

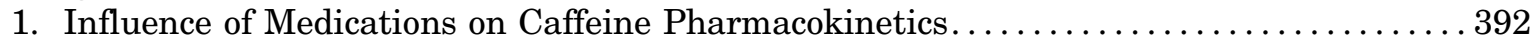

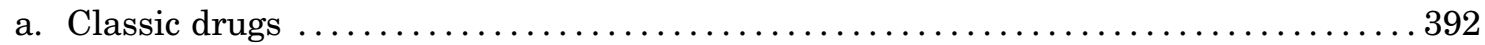

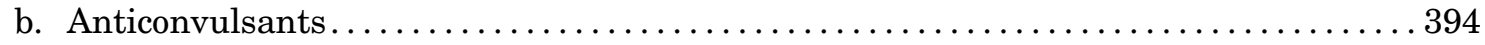

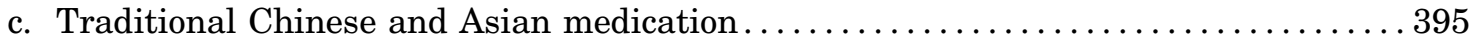

2. Influence of Caffeine on the Effects of Some Medications . . . . . . . . . . . . . . 396

IV. The Role of Tolerance in the Variability of Caffeine Consumption . . . . . . . . . . . . . . . 397

V. Interindividual Differences Due to Genetic Factors . . . . . . . . . . . . . . . . . . 397

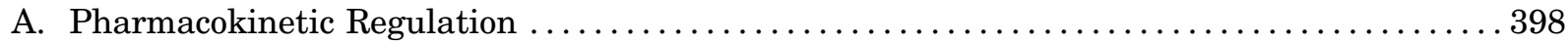

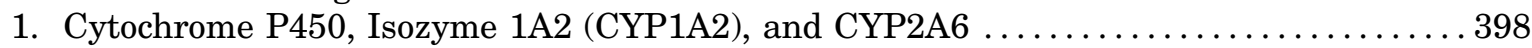

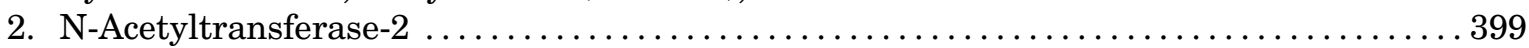

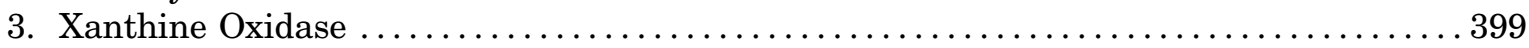

4. Polymorphisms of Enzymes Metabolizing Caffeine and Their Consequences on

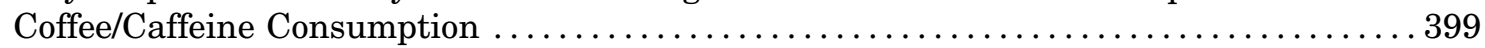

5. Influence of CYP1A2 and Aryl-hydrocarbon Receptor Genetic Variability in Specific

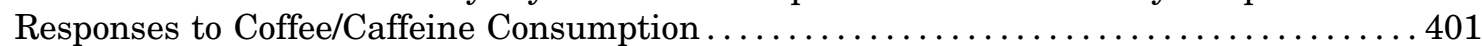

B. Pharmacodynamic Regulation. .................................401

1. Polymorphisms at the Adenosine A2A Receptor and Adenosine Deaminase Genes ....401

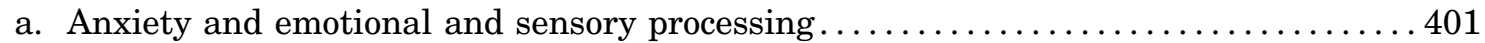

Address correspondence to: Astrid Nehlig, INSERM U 1129, Pediatric Neurology, Necker-Enfants Malades Hospital, University of Paris Descartes, Inserm U1129, Paris, France. E-mail: nehliga@unistra.fr

This work was supported by a grant from the Institute for Scientific Information on Coffee (ISIC), La Tour-de-Peilz (Switzerland).

The author of the current work received funding from ISIC, which is a not-for-profit organization founded in 1990 devoted to the study and disclosure of science related to coffee and health. The author assures that funding obtained from ISIC has not in any way affected the production or content of the current study. Finally, the author of the current work declares that there is no duality of interest associated with this work.

https://doi.org/10.1124/pr.117.014407. 


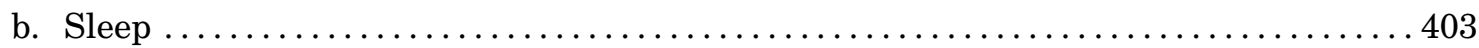

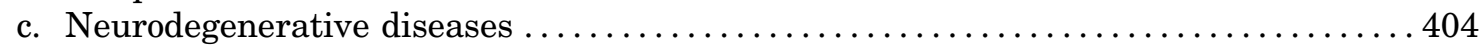

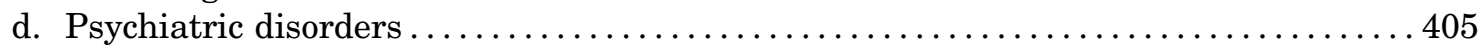

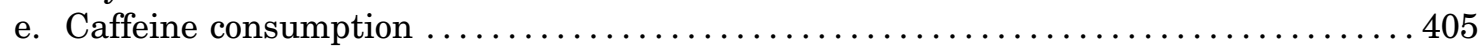

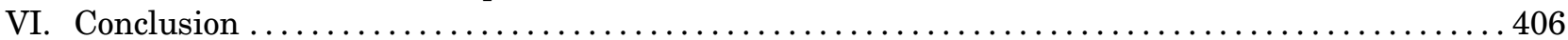

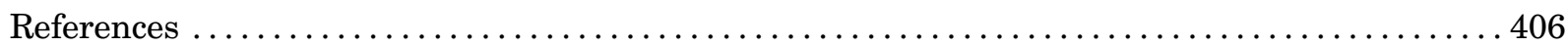

Abstract-Most individuals adjust their caffeine intake according to the objective and subjective effects induced by the methylxanthine. However, to reach the desired effects, the quantity of caffeine consumed varies largely among individuals. It has been known for decades that the metabolism, clearance, and pharmacokinetics of caffeine is affected by many factors such as age, sex and hormones, liver disease, obesity, smoking, and diet. Caffeine also interacts with many medications. All these factors will be reviewed in the present document and discussed in light of the most recent data concerning the genetic variability affecting caffeine levels and effects at the pharmacokinetic and pharmacodynamic levels that both critically drive the level of caffeine consumption. The pharmacokinetics of caffeine are highly variable among individuals due to a polymorphism at the level of the CYP1A2 isoform of cytochrome P450, which metabolizes 95\% of the caffeine ingested. Moreover there is a polymorphism at the level of another critical enzyme, $N$-acetyltransferase 2. At the pharmacodynamic level, there are several polymorphisms at the main brain target of caffeine, the adenosine A2A receptor or ADORA2. Genetic studies, including genome-wide association studies, identified several loci critically involved in caffeine consumption and its consequences on sleep, anxiety, and potentially in neurodegenerative and psychiatric diseases. We start reaching a better picture on how a multiplicity of biologic mechanisms seems to drive the levels of caffeine consumption, although much more knowledge is still required to understand caffeine consumption and effects on body functions.

\section{Introduction}

Caffeine is the most widely consumed psychostimulant worldwide. Caffeine is naturally present in variable amounts in the beans, leaves, and fruits of over 60 plants. Roasted coffee beans and tea leaves are the primary sources of dietary caffeine (Barone and Roberts, 1996). Caffeine is also found in kola nuts, cocoa beans, yerba mate, and guarana berries. Caffeine is ingested most frequently in drinks such as coffee (71\%), soft drinks (16\%), and tea (12\%) (Heckman et al., 2010). Over the last two decades or so, functional beverages, such as energy drinks, caffeinated sport drinks, juices, and waters have been introduced. In addition, caffeine is also found in cocoa, chocolate, and medications such as antipain formulations and dietary supplements.

The United States Food and Drug Administration established that caffeine is generally recognized as safe when consumed in cola-type beverages up to a concentration of $0.02 \%$. The average caffeine consumption from all sources amounts to about $70 \mathrm{mg} /$ person per day Approximately $90 \%$ of adults report regular caffeine use, with an average daily intake of $227 \mathrm{mg}$. The main sources of caffeine for adults are coffee $(70 \%)$, cola drinks (16\%), and tea (12\%) (Frary et al., 2005). In the United States, the highest caffeine intake was recorded in middle-aged consumers (50-64 years). In children and adolescents, soft drinks and tea are the major contributors to caffeine consumption. Finally, energy drink consumers represent up to $10 \%$ of all age groups (Heckman et al., 2010).

Recently, based on a literature review concerning the effects of caffeine on the central nervous system and on the cardiovascular system, the European Food Safety Agency [European Food Safety Authority (EFSA), 2015] has established safe levels of caffeine consumption in the population. Adults are advised to limit their caffeine consumption in one sitting to $200 \mathrm{mg}$ (about two regular $125 \mathrm{ml}$ cups of coffee) and to $400 \mathrm{mg}$ over a daytime period. Pregnant women should not go over $200 \mathrm{mg}$ caffeine per day, and for children and adolescents, the safe limit is set at $3 \mathrm{mg} / \mathrm{kg}$ per day.

There is a large interindividual variability in caffeine consumption and in its effects on the human body. The daily consumption of coffee/caffeine in various individuals ranges from zero to very high levels (that can sometimes be well above the EFSA advised levels of consumption) and most reasons underlying this interindividual variability are not clearly understood. Various factors that could contribute have been identified over the years, including age, sex, hormones, type of activity, coingestion with food. In the last two decades or so, numerous genetic studies aimed at clarifying how the genetic variability in the enzymes metabolizing caffeine and in the expression of adenosine receptors, mainly the $\mathrm{A}_{2 \mathrm{~A}}$ receptor underlying most of the physiological effects of caffeine in the body and brain, might

ABBREVIATIONS: AD, Alzheimer disease; ADA, adenosine deaminase; ADORA2A, adenosine A2A receptor; AED, antiepileptic drug; AHR, aryl-hydrocarbon receptor; ASD, autism spectrum disorder; BDNF, brain-derived neurotrophic factor; CBZ, carbamazepine; GCKR, glucokinase regulatory protein; GWAS, genome-wide association studies; MDMA, 3,4-methylenedioxymethamphetamine; 1MU, 1-methyluric acid; 1MX, 1-methylxantine; NAT2, N-acetyltransferase-2; PD, Parkinson disease; PPI, prepulse inhibition paradigm; RR, relative risk; SNP, single nucleotide polymorphism; $\mathrm{XO}$, xanthine oxidase. 
underlie the pharmacokinetics and pharmacodynamics of caffeine and hence the sensitivity of different population subsets to the effects of caffeine ingestion. In the present review, we will consider the different factors that might influence caffeine availability in the body and the impact of coffee/caffeine consumption on functional activity. Caffeine exerts a wide range of effects on the body, both positive and negative, that might partly influence the variability of caffeine intake between the different individuals. The benefits and risks of caffeine intake are summarized in Table 1.

\section{Caffeine Metabolism and Pharmacokinetics}

Caffeine metabolism and pharmacokinetics have been extensively studied in the past and revised recently (Arnaud, 2011).

\section{A. Absorption}

Absorption and bioavailability of caffeine are relatively comparable in all species, humans, dogs, rabbits, and mice (Walton et al., 2001). In both animals and humans, caffeine is rapidly and completely absorbed in the gastrointestinal tract. In humans, $99 \%$ of caffeine ingested is absorbed within 45 minutes (Blanchard and Sawers, 1983a), 20\% at the level of the stomach and the largest part in the small intestine (Chvasta and Cooke, 1971). In healthy adult men absorbing $5 \mathrm{mg} / \mathrm{kg}$ caffeine, the peak plasma caffeine concentration $(10 \mu \mathrm{g} / \mathrm{ml})$ is reached in 30 minutes (Blanchard and Sawers, 1983a). The plasma concentration of caffeine decreases more rapidly than that of paraxanthine, its main metabolite. The concentrations of paraxanthine become even higher than those of caffeine at about 8-10 hours after caffeine ingestion and this occurs in all species (Bonati et al., 1982; Arnaud, 1993). This is critical given that paraxanthine is as potent as caffeine for the blockade of adenosine receptors (Fredholm et al., 1999) and hence studies on the biologic effects of caffeine ingestion should take into account the presence of metabolites, at least paraxanthine together with caffeine. In humans, caffeine pharmacokinetics is independent from the route of administration implying limited hepatic first-pass effect. Percutaneous caffeine is effectively absorbed in premature infants suffering from apnea (Morisot et al., 1990). Inhalation of the sublimate of a $100 \mathrm{mg}$ tablet caffeine shows effective and rapid absorption, with an approximate bioavailability of

TABLE 1

Benefits and risks of exposure to caffeine

Data according to Kawachi et al. (1996), Ferré (2008), Goldstein et al. (2010), Nehlig (2010), Lucas et al. (2011), Caldeira et al. (2013), Derry et al. (2014), Panza et al. (2015), Doepker et al. (2016), Zuchinali et al. (2016), Grosso et al. (2017).

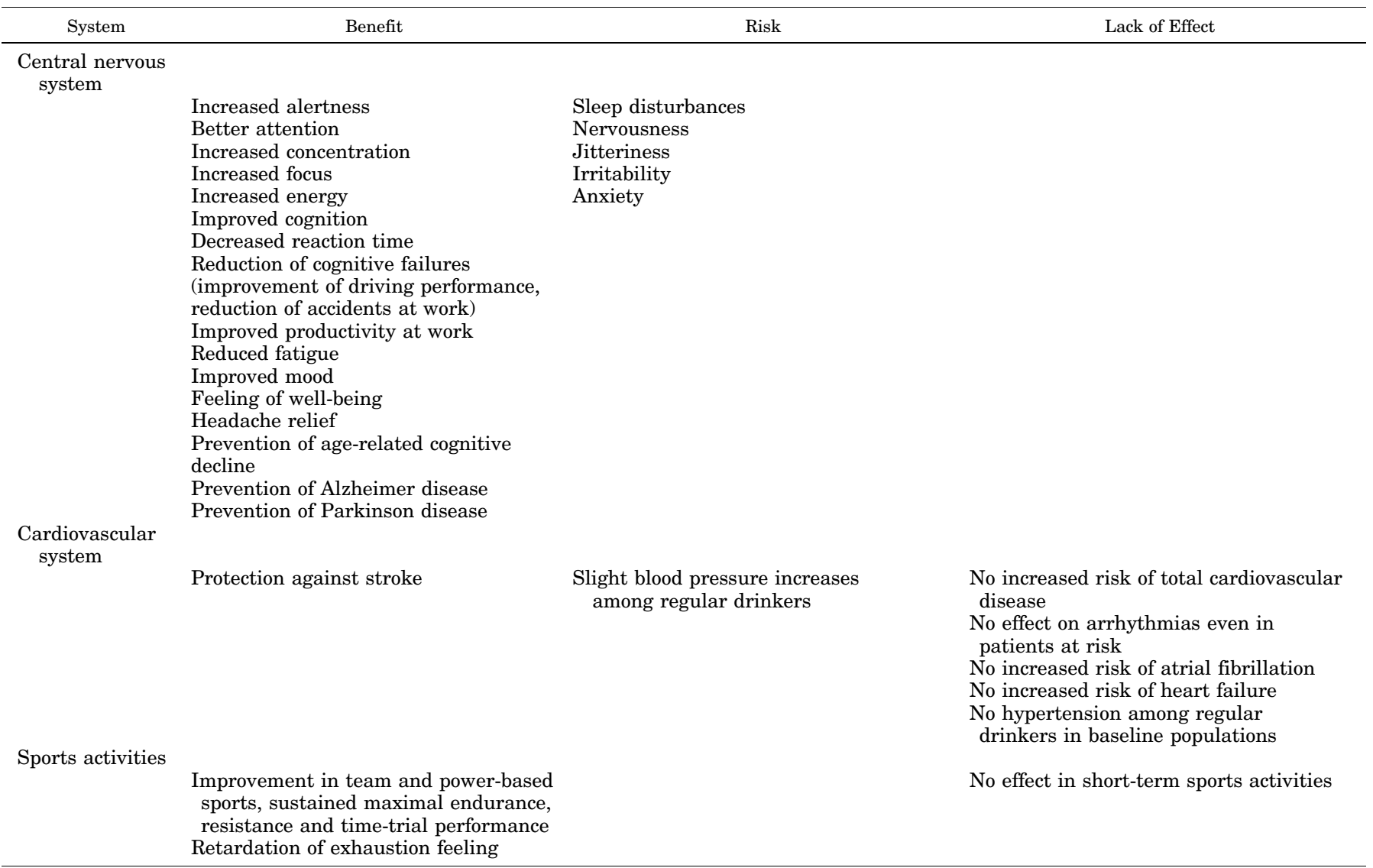


$60 \%$ in experienced smokers. The pharmacokinetics of caffeine after inhalation and intravenous administration are quite similar (Zandvliet et al., 2005).

Caffeine absorption from food and beverages does not depend on age, sex, genetic background, and disease or simultaneous exposure to drugs, alcohol, and nicotine. Caffeine in tea and coffee are absorbed at a similar speed (Marks and Kelly, 1973). Caffeine absorption from cola and chocolate is delayed ( $\mathrm{T}_{\max }$ of 1.5-2 hours) compared with a caffeine capsule ( $\mathrm{T}_{\max }$ of 30 minutes) or with coffee and tea as drinks, and the $C_{\max }$ values are reduced by about $25 \%$ for both drinks compared with $2.05 \mu \mathrm{g} / \mathrm{ml}$ for a capsule, resulting most likely from of their acidic $\mathrm{pH}$ (Marks and Kelly, 1973; Mumford et al., 1996).

\section{B. Distribution}

Caffeine enters the tissue water compartment and is evenly distributed in all body fluids such as blood plasma including umbilical cord blood, cerebrospinal fluid, saliva, bile, semen, breast milk, and all organs. Using radiolabeled molecules, it was shown in rats that caffeine or its metabolites do not accumulate in the body (Arnaud, 1976). In saliva, caffeine concentration reaches $65 \%-85 \%$ of plasma levels (Callahan et al., 1982). This easy measurement is often used to monitor noninvasively compliance to or abstinence of caffeine.

One hour after the intravenous injection of caffeine to rabbits, the tissue-to-blood caffeine concentration ratio is close to 1 , with the exception of fat (0.2), adrenals (0.6), liver (1.5), and bile (2.7) (Beach et al., 1985).

Caffeine is lipophilic enough to cross all cellular membranes, including the blood-brain barrier and the placental barrier (Lachance et al., 1983; Tanaka et al., 1984), contrary to its dimethylxanthine metabolites (Tanaka et al., 1984; Debry, 1994). Caffeine crosses the placenta by passive diffusion (Tanaka et al., 1984), and occasionally high levels of caffeine have been measured in premature infants born to women who were heavy caffeine consumers (Khanna and Somani, 1984). Caffeine is readily distributed to the fetus and equilibrium is always maintained between the mother and the fetus. Likewise, caffeine enters maternal milk, but the concentration is lower in breast milk than in serum, reaching reported ratios of $0.52-0.81$ (Arnaud, 1993). In pregnant women, caffeine levels in the urine and umbilical cord blood only reflect the intake close to the time of sampling but not over pregnancy (Grosso et al., 2008).

The blood-to-plasma ratio is close to 1 (Bonati et al., 1984-1985), reflecting limited plasma protein binding and free movements into and out of blood cells. There is no blood-brain barrier to caffeine (Lachance et al., 1983; Tanaka et al., 1984). In fetal or adult animals, caffeine enters the brain by both simple diffusion and saturable, carrier-mediated transport. In newborn infants, caffeine concentration is similar in plasma and cerebrospinal fluid (Turmen et al., 1979; Somani et al., 1980).

\section{Excretion}

In humans and animals, renal excretion predominates. In humans, about $70 \%$ of a $7.5 \mathrm{mg} / \mathrm{kg}$ oral caffeine dosage is recovered in urine (Tang-Liu et al., 1983) with $0.5 \%-2 \%$ excreted unmetabolized in urine. The low caffeine urine excretion is explained by $98 \%$ caffeine reabsorption from the renal tubule once it has been filtered by the glomeruli. This indicates that the ratelimiting factor in caffeine plasma clearance is metabolism (Arnaud, 1993). To the best of my knowledge, there is no information available on the renal tubule reabsorption of the dimethylxanthines, especially of the main metabolite paraxanthine. Urine and plasma caffeine concentration have been reported to be in good correlation (Birkett and Miners, 1991). In the feces, $2 \%-$ $7 \%$ of the caffeine dose is excreted over 48 hours. A large part of this excretion was found to be mainly caffeine metabolites secreted after liver-intestine cycling and metabolism (Arnaud, 1976). The compounds found in human feces after caffeine ingestion were 1,7-dimethylxanthine (44\%), 1-dimethyluric acid (38\%), 1,3-dimethyluric acid (14\%), 1,3,7-trimethyluric acid (6\%), and caffeine (2\%) (Callahan et al., 1982). Favorable effects of coffee consumption on the composition of gut microbiota have been reported (Jaquet et al., 2009), but the effects of caffeine alone are unknown.

\section{Pharmacokinetics}

There are considerable pharmacokinetic differences between humans and different animal species, making it difficult to extrapolate from one species to the next.

In healthy humans, caffeine is apparently eliminated via first-order kinetics in a one-compartment open model system for intakes ranging from 2 to $10 \mathrm{mg} / \mathrm{kg}$ (Bonati et al., 1982; Blanchard and Sawers, 1983a). The first-pass metabolism for caffeine is minimal (Arnaud, 1993). Dose-dependent kinetics was observed with plasma levels of caffeine over $30 \mu \mathrm{g} / \mathrm{ml}$; this was reported in the case of an infant acutely intoxicated (Jarboe et al., 1986). However, in adults, some metabolic pathways can saturate at lower levels, $1-4 \mathrm{mg} / \mathrm{kg}$, mainly the demethylation of caffeine to paraxanthine (Tang-Liu et al., 1983; Arnaud and Enslen, 1992). Several in vivo tests suggest that caffeine metabolism is dose-dependent, leading to nonlinear clearance (Denaro et al., 1990) and saturable between 70 and $300 \mathrm{mg}$ (Cheng et al., 1990).

In addition to the dose, the plasma kinetics of caffeine might be influenced by the presence of dietary constituents in the stomach or gastric pathologies that may delay gastric emptying (Brachtel and Richter, 1988; Arnaud, 1993). Fluid intake may also modify total body clearance and affect renal clearance and pharmacokinetics of caffeine (Trang et al., 1985). Circadian variation in caffeine clearance is limited in most individuals (Hashiguchi et al., 1992). Most of the 
variations in caffeine kinetics are accounted for by genetic and environmental factors that will be detailed below.

After a single dose of $4 \mathrm{mg} / \mathrm{kg}$ caffeine, plasma concentrations of caffeine in humans were recorded reach highest levels at 1 to 2 hours, and the half-lives range from 2.5 to 5 hours (Arnaud, 1993). Larger variations in half-lives ranging from 2.3 to 9.9 hours have been reported that indicate that caffeine clearance might undergo significant interindividual variability (Blanchard and Sawers, 1983a). After oral administration, the total plasma clearance of caffeine and paraxanthine is identical $(2.07-2.20 \mathrm{ml} / \mathrm{min}$ per $\mathrm{kg})$. The unbound plasma clearance of caffeine and paraxanthine is comparable (3.11-4.14 $\mathrm{ml} / \mathrm{min}$ per $\mathrm{kg}$ ) and about 2- to 3-fold higher than those of theophylline and theobromine (1.61 and $1.39 \mathrm{ml} / \mathrm{min}$ per $\mathrm{kg}$ ) (Lelo et al., 1986a). In nonsmoking subjects, caffeine undergoes mean partial clearance to paraxanthine at a rate that is about 8 - and 23 -fold higher than that to theophylline and theobromine, respectively. This large difference confirms that paraxanthine is the major caffeine metabolite and should be taken into consideration when studying caffeine effects on the body (Lelo et al., 1986b).

The primary metabolites of caffeine, paraxanthine, theobromine, and theophylline are biologically active. Theophylline has been used as a bronchodilator in asthma and acts on inflammatory pathways (production of interleukin-6, tumor necrosis factor- $\alpha$ ). Theophylline antagonizes $\mathrm{A}_{1}, \mathrm{~A}_{2 \mathrm{~A}}$, and $\mathrm{A}_{2 \mathrm{~B}}$ adenosine receptors (Haskó and Cronstein, 2011). In addition, theophylline acts on histone acetylation pathways favoring deacetylation, and hence reducing the expression of inflammatory genes and proteins (Ito et al., 2002). Paraxanthine is as potent as caffeine for the blockade of adenosine receptors (Fredholm et al., 1999). The biologic effects of theobromine are rather minor. However, theobromine is a precursor of pentoxyphylline, an inhibitor of cytokines with potential therapeutic action on alcoholic liver disease. However, according to the conclusions of a recent Cochrane study, at this point no clear conclusions can be made concerning the potential effects of pentoxifylline in patients with alcoholic hepatitis (Whitfield et al., 2009). At this point, most of the research available is concentrated on caffeine and, to the best of my knowledge, no paper has considered the potential role of caffeine metabolites together with caffeine in the biologic effects of the trimethylxanthine.

\section{E. Metabolism}

Caffeine is primarily metabolized in the liver where it undergoes successive demethylations and a C8 oxidation (Fig. 1). CYP1A2 is found only in the liver. It represents $15 \%$ of all cytochrome $\mathrm{P} 450$ in the human liver and accounts for more than $90 \%$ of caffeine metabolism (Arnaud, 2011). CYP1A2 catalyzes the 1-, 3-, and 7-demethylations of caffeine, the 7-demethylation of paraxanthine, and the 1- and 3-demethylations of theophylline. CYP1A2 is virtually responsible for most of the biochemical reactions concerning caffeine and its metabolites. Caffeine biotransformation by CYP1A2 accounts for a mean value of $84 \%$ for paraxanthine, $12 \%$ for theophylline, and $4 \%$ for theobromine. On the other hand, CYP2E1 is predominantly responsible for the formation of theophylline and theobromine ( $\mathrm{Gu}$ et al., 1992). CYP2D6-Met also catalyzes caffeine demethylation and 8-hydroxylation, whereas CYP2E1 plays a more minor role in these pathways. CYP3A4 predominantly mediates 8-hydroxylation and may be involved in the in vivo synthesis of 1,3,7-TMU (trimethylurea). Thus, at least four CYP isoforms contribute to caffeine metabolism at a $3 \mu \mathrm{mol} / \mathrm{ml}$ caffeine concentration. Below a 0.1 $\mu \mathrm{mol} / \mathrm{ml}$ level, CYP1A2 and CYP1A1 are the two cytochrome $\mathrm{P} 450$ isoenzymes predominantly involved (Ha et al., 1996).

$N$-Acetyltransferase-2 (NAT2) is also involved in caffeine metabolism and catalyzes the conversion of paraxanthine to 5-acetylamino-6-formylamino-3methyluracil. Once the genotype has been taken into account, acetylation activity is not influenced by sex, race, age, education, physical activity, weight, and consumption of coffee, alcohol, red and processed meat, cruciferous vegetables, smoking, use of estrogens (Le Marchand et al., 1996).

Finally, xanthine oxidase (XO) catalyzes the conversion of 1-methylxantine (1MX) to 1-methyluric acid (1MU). The ratios used to measure xanthine oxidase activity follow a normal distributed (Vistisen et al., 1992). In the Japanese population, low xanthine oxidase activities are found in $11 \%$ of the subjects that show a mean urinary uric acid concentration $53 \%$ lower than in the general population (Saruwatari et al., 2002).

The largely variable activity of CYP1A2 between subjects influences the disposition of caffeine (Landi et al., 1999) and might reflect differences linked to sex, race, genetic polymorphisms, disease, and exposure to various metabolic inducers (Rasmussen et al., 2002).

There are two interethnic variations, one related to acetylation polymorphism and the other one reflecting a difference in paraxanthine excretion. Both might be linked to ethnic differences in renal functions (Kalow, 1986). Only $11 \%$ of Japanese men and women living in Kyushu are slow acetylators (Saruwatari et al., 2002). In the Danish population, NAT2 activity is distributed in a bimodal way with $47 \%$ fast and $53 \%$ slow acetylators (Vistisen et al., 1992). In another study on a mixed population, CYP1A2 values of most subjects were found to cover a 6.3 -fold range, whereas the range was reduced to 1.7-fold range for XO. There were no differences between Asian and European subjects (Kalow and 


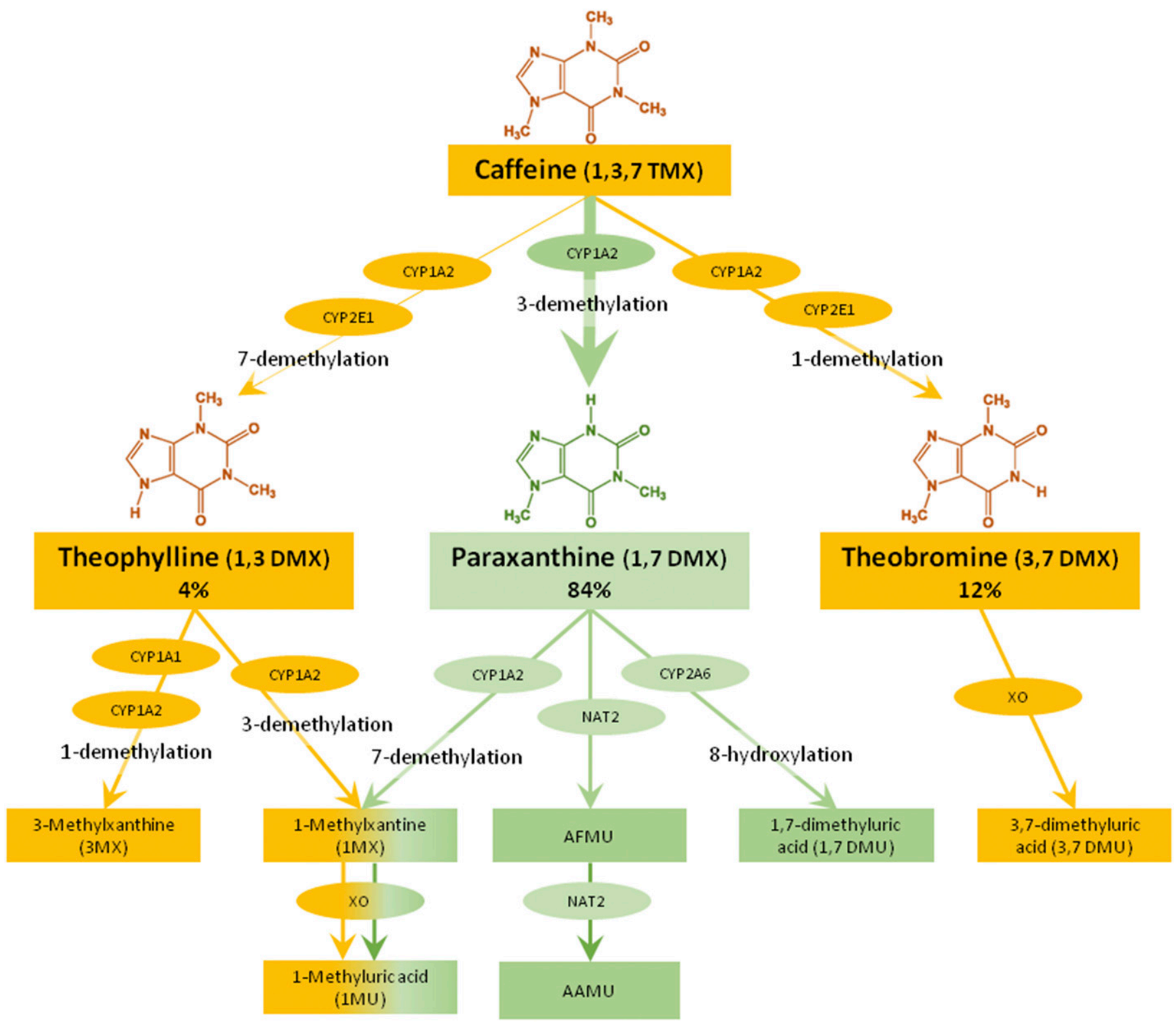

Fig. 1. Main pathways and enzymes involved in caffeine degradation. The orange color was used, starting with the first step of caffeine degradation, for the metabolic pathways concerning theophylline and theobromine, while the green color was used for paraxanthine, which is the main metabolite of caffeine and has powerful biological effects. The numbers indicate the percentages of metabolites obtained after caffeine metabolism. AAMU, 5-acetylamino-6-amino-3-methyluracil; AFMU, 5-acetylamino-6-formylamino-3-methyluracil; CYP, cytochrome P450 followed by the number corresponding to each specific isoform; NAT2, $N$-acetyltransferase-2; XO, xanthine oxidase.

Tang, 1991a). The combined slow CYP1A2/rapid NAT2 is more common in Africans than in Caucasians (25 vs. $15 \%, P<0.02$ ), but ethnicity does not significantly influence in the proportion of slow and rapid CYP1A2 phenotypes or the combined slow NAT2/rapid CYP1A2 phenotype (Muscat et al., 2008).

\section{Effect of Various Factors on Caffeine Metabolism}

Caffeine metabolism is affected by many exogenous and endogenous factors such as genetic determinants, age, sex, pregnancy, diet, lifestyle, smoking, environmental factors, medications, and diseases.

\section{A. Age}

In human newborns, the elimination of caffeine is considerably slowed down because of the immaturity of hepatic enzymes metabolizing caffeine. The caffeine elimination half-life and clearance decrease linearly with gestational age and exponentially after birth, reaching a plateau during the second trimester of postnatal life (Pons et al., 1988). In neonates, caffeine plasma half-live is prolonged and reaches $65-103$ hours. This duration decreases rapidly to 14.4 hours by $3-$ 5 months, 2.6 hours at 5 to 6 months to reach $2.2-3.5$ hours in adults. In premature neonates, apnea is treated with either theophylline or caffeine. In this age population, theophylline is metabolized to caffeine via 
a methylation reaction, whereas in adults, the major metabolic pathway involves oxidative reactions, namely demethylation and oxidation, as shown in Fig. 1 (Bory et al., 1979).

The pharmacokinetics and bioavailability of caffeine are rather similar in young men about 20 years old and elderly about 71 years old (Blanchard and Sawers, 1983b). In humans, age does not appear to affect caffeine clearance, whereas in the rat, caffeine half-life increases in an age-related manner (Arnaud, 2011). Likewise, age does not affect the volume of caffeine distribution, i.e., the distribution of caffeine in intracellular water, which reaches $0.5-0.8 \mathrm{l} / \mathrm{kg}$ (Bonati et al., 1984-1985; Debry, 1994).

\section{B. Sex and Hormones}

1. Sex, Pregnancy, and Contraception. Although CYP1A2, the main enzyme responsible for caffeine clearance, is more active in men than in women, no sex difference was found in caffeine metabolism when based on urinary metabolite patterns or ratios (for review, see Arnaud, 2011).

During pregnancy, the excretion of 1-methylxantine (1MX) and 1-methyluric acid (1MU) increase (Scott et al., 1986), as a result of significantly increased hydroxylation. In late pregnancy, CYP1A2, xanthine oxidase, and NAT2 activities decrease (Bologa et al., 1991). Pregnancy and smoking in women using oral contraceptives reduces the caffeine metabolic ratio in $29 \%$ and $20 \%$, respectively, compared with controls reflecting diminished activity of CYP1A2 (Vistisen et al., 1991). Metabolic ratios for CYP1A2 during all three trimesters of pregnancy are significantly lower than the ratio after delivery. A lower metabolic ratio during pregnancy was also reported for NAT2 (Tsutsumi et al., 2001). A 2.8-fold higher plasma caffeine-to-paraxanthine ratio in oral contraceptive (ethinylestradiol) users compared with controls confirms the inhibition of CYP1A2 by oral contraceptives (Rasmussen et al., 2002; Granfors et al., 2005).

During pregnancy, caffeine half-life is prolonged mainly during the third trimester and returns to prepregnancy levels within a few weeks after delivery (Arnaud, 1993). Caffeine half-life increases up to 11.518 hours toward the end of pregnancy compared with the habitual 2.5-5 hour half-life. Daily consumption leads to caffeine accumulation in the fetus, because neither the fetus nor the placenta are able to metabolize caffeine (Grosso and Bracken, 2005). A recent prospective pharmacokinetic study including 59 pregnant women (93.2\% white) studied once per trimester confirmed these data and showed a significant increase in the dose-normalized concentrations of caffeine in serum and urine and in the caffeine urine/serum concentration ratio when comparing the first and third trimesters. Similarly, normalized concentrations of theophylline in serum and urine increased significantly during the third trimester. These data confirm that caffeine metabolism is decreased during the last 3 months of pregnancy (Yu et al., 2016).

Caffeine half-life also fluctuates with the estrus cycle. Systemic clearance of caffeine was slower in the luteal phase, an effect related to the proximity of menstruation onset and to levels of progesterone, although the half-life does not differ (Lane et al., 1992). All pharmacokinetic parameters are similar between women not taking any oral contraceptives and men, except the intracellular volume of distribution, which is larger in women than in men (McLean and Graham, 2002). Oral contraceptive use almost doubles caffeine half-life (Arnaud, 1993). Oral contraceptives increase the halflife of caffeine from 6.2 hours in untreated to 10.7 hours in treated women, mainly during the second part of the cycle, the luteal phase (Bruguerolle et al., 1990; Lane et al., 1992). The effect is already observed after 2 weeks of treatment and slightly increased after 6 weeks on oral contraceptive steroids (Rietveld et al., 1984). However, the use of oral contraceptives does not affect the volume of caffeine distribution.

2. Sex, Aging, and Neurodegenerative Diseases. The research on age-related cognitive decline and neurodegenerative diseases has reported sex-related differences in the effects of caffeine on cognition and/or the evolution of the disease.

In Parkinson disease (PD), the potential preventive effect of lifelong coffee/caffeine exposure on the risk of developing the disease is different in men and women. The effects of caffeine are not as marked in women as in men (Ascherio et al., 2001) and appear to be modified by postmenopausal hormone replacement therapy (Ascherio et al., 2004). Compared with men, whose relative risk (RR) of developing $\mathrm{PD}$ is reduced by $57 \%$ for the higher consumption quartile ( $435 \mathrm{mg} /$ day) compared with the lower one $(5.6 \mathrm{mg} /$ day $)$, the $\mathrm{RR}$ for all women is $39 \%$, but the association is stronger in nonhormone users $(R R=0.32)$ than in hormone users $(\mathrm{RR}=0.81)$ (Palacios et al., 2012; Qi and Li, 2014). Estrogens are competitive inhibitors of caffeine metabolism (Pollock et al., 1999) and act on the nigrostriatal dopaminergic system (Shulman, 2002). A polymorphism of the main cytochrome P450, CYP1A2, is marginally associated with increased risk of $\mathrm{PD}$ in women but not in men. Likewise, two polymorphisms at the level of the estrogen receptors ESR1 and ESR2 interact with caffeine but are of marginal significance (Palacios et al., 2010).

The mechanisms underlying this difference have been explored in an animal model of PD, the mouse 1-methyl-4-phenyl-1,2,3,6-tetrahydropyridine model. In this model, the authors did not find any caffeineinduced reduction of 1-methyl-4-phenyl-1,2,3,6tetrahydropyridine-induced striatal dopaminergic loss in females compared with males. After ovariectomy, there was less caffeine-induced neuroprotection in 
females treated with estrogens compared with those treated with placebo. In addition, estrogen treatment also prevented caffeine-linked protection of dopaminergic neurons in males. Thus, estrogens are able to prevent the neuroprotective effect of caffeine in a model of PD neurodegeneration, and the interaction between estrogen and caffeine is clearly able to modify the risk of PD (Xu et al., 2006).

Several studies reported a protective role on agerelated cognitive decline, most often either limited to women (Johnson-Kozlow et al., 2002; Ritchie et al., 2007; Arab et al., 2011) or more pronounced in women than in men (Santos et al., 2010). The effect was also reported as more prominent in the female population over 80 (Ritchie et al., 2007). Again, the mechanisms underlying these effects are not well understood and might underlie specific sex/age-related effects of caffeine.

In Alzheimer disease (AD), the data concerning the association of caffeine consumption and dementia do not all start at the same point of disease evolution and have too limited recruitments to allow drawing any conclusion on sex difference. However, the susceptibility to $\mathrm{AD}$ might be modulated by the other enzyme responsible for caffeine metabolism and elimination, NAT2. Some literature reports, but not all, seem to link the expression of this gene to potential pathogenesis of $\mathrm{AD}$, mainly the NAT2 rapid acetylating phenotypes (Rocha et al., 1999; Guo et al., 2004).

\section{Obesity}

The apparent volume of distribution of caffeine is increased by $60 \%$ in obese subjects, but obesity has no effect on caffeine clearance and seems to prolong caffeine half-life by 31\%-69\% (Abernethy and Todd, 1985; Kamimori et al., 1987). However, a more recent study found that in subjects with severe obesity, caffeine half-life and clearance rate are only minimally affected by obesity, whereas the volume of distribution of caffeine is increased. The effect is more marked in women. According to the latter study, the dosage of caffeine-containing drugs in subjects with obesity does not need to be significantly modified (Caraco et al., 1995). In patients with Type 1 and Type 2 diabetes, the various pharmacokinetics of caffeine are unchanged (Matzke et al., 2000).

\section{Liver Disease}

In humans with various liver diseases such as cirrhosis and hepatitis B or C, the plasma clearance of caffeine is largely reduced in correlation with the severity of the disease (Park et al., 2003). This effect reflects the delay in the synthesis of paraxanthine (Jodynis-Liebert et al., 2004). In hepatic alcoholic cirrhosis, plasma half-life of caffeine was reported to increase in the range of 50-160 hours (Scott et al., 1988), plasma binding of caffeine is reduced by $19 \%$, plasma clearance by $40 \%$, with all these affected pathways contributing to impaired elimination of caffeine in cirrhosis (Desmond et al., 1980).

\section{E. Smoking}

Most studies reported that smoking stimulates caffeine clearance (for review, see Arnaud, 2011). Cigarette smoking almost doubles the rate of caffeine metabolism as a result of enzyme induction by polycyclic aromatic hydrocarbons that increase the activity of liver enzymes. These differences most likely reflect the induction of the activity of hepatic aryl hydrocarbon hydroxylase in smokers (Parsons and Neims, 1978; Kalow and Tang, 1991b). The time course changes in CYP1A2 are very rapid, with an initial caffeine clearance decrease of $36 \%$ upon smoking cessation (Faber and Fuhr, 2004).

After smoking cessation, ongoing caffeine consumption has been associated with more than a twofold increase in plasma levels of caffeine. Cessation of smoking significantly reduces caffeine clearance and changes the pattern of caffeine metabolism bringing the two steps of caffeine demethylation back to normal (Brown et al., 1988). Three weeks after smoking cessation and continued caffeine use, caffeine concentrations reach 203\% of baseline for caffeine users (Swanson et al., 1997).

\section{F. Diet and Alcohol}

In neonates treated for apnea, formula-fed infants experience a nearly threefold increase of caffeine clearance compared with breast-fed infants. CYP1A2 is significantly induced by cow milk-based formula but not by human milk (Xu et al., 2005). In formula-fed infants caffeine metabolic pathways undergo more rapid maturation than in breast-fed infants. This difference is linked to an increase in the activity of CYP1A2 and reflects the potential dietary modulation of CYP1A2 activity (Blake et al., 2006).

The regular consumption of caffeine on its own metabolism is controversial. Two studies found that daily intake of high doses of caffeine over 1 week did not influence caffeine pharmacokinetics (George et al., 1986; Chen et al., 2009b). On the other hand, one study found that the consumption of at least three cups of coffee per day stimulated CYP1A2 activity (Djordjevic et al., 2008).

Grapefruit juice consumption decreases caffeine clearance by $23 \%$ and prolongs caffeine half-life by $31 \%$ (Fuhr et al., 1993, 1995). Consumption of broccoli and brassica vegetables in general (Lampe et al., 2000) and absorption of large quantities of vitamin $\mathrm{C}$ increase caffeine clearance (Blanchard and Hochman, 1984). Apiaceous vegetables (carrots, celery, parsley, caraway, fennel, etc.) decrease CYP1A2 activity compared with a basal and allium diet (Lampe et al., 2000). In South Asians, the activity of CYP1A2 is lower than in other 
populations, because Asians cook their food quite regularly in curries containing ingredients such as curcumin and turmeric that downregulate the activity of CYP1A2 (Chen et al., 2010). The flavonoid quercetin affects the metabolism of caffeine and paraxanthine and mainly decreases the urinary excretion of the latter compound by $32 \%$; it changes also the excretion of several other metabolites of caffeine (Chen et al., 2009b). In elderly institutionalized subjects receiving a balanced diet, the plasma paraxanthine-to-caffeine ratio was found to be identical in adequately nourished or undernourished subjects with marked weight loss (Hamon-Vilcot et al., 2004).

Alcohol has an inhibitory effect on CYP1A2 activity (Le Marchand et al., 1997), and consumption of $50 \mathrm{~g} / \mathrm{day}$ alcohol significantly increases caffeine half-life by $72 \%$ and reduces clearance by $36 \%$ (George et al., 1986). The bioavailability of alcohol or caffeine is not significantly different whether the two substances are taken alone or in combination (Azcona et al., 1995). Caffeine does not modify the motor or psychologic symptoms of alcoholic intoxication (Azcona et al., 1995) nor does it wipe out the negative effects of alcohol on driving abilities despite its effects on vigilance and reaction time (Liguori and Robinson, 2001; Howland et al., 2011). Interestingly, the simple expectancy for consuming caffeine is able to reduce the effects of alcohol on inattention, and expecting or consuming caffeine may counteract some alcoholinduced performance decrements (Heinz et al., 2013). However, the compensation for alcohol-related impairments is only found in people that believe that caffeine will counteract alcohol effects (Fillmore et al., 2002). Binge coconsumption of caffeine and alcohol, as often found now in teenagers using energy drinks mixed with alcohol, has been studied in a mouse model. It does not lead to alcohol-induced sedation but rather to a highly stimulated state that can be qualified as a "wide awake drunk" state (Fritz et al., 2014).

\section{G. Drugs}

Caffeine pharmacokinetics appear to be influenced by drugs affecting the activity of CYP1A2 via autoinduction or by treatment with some medications. Therefore, in patients taking caffeine-containing medicine or in coffee drinkers taking drugs interacting with CYP1A2, specific dosage adjustments may be required upon caffeine ingestion and cessation. On the other hand, caffeine can also modify the effect and kinetics of some medications. Both traditional medicine and supplements prepared from plant extracts might affect caffeine pharmacokinetics.

\section{Influence of Medications on Caffeine} Pharmacokinetics.

a. Classic drugs. Many drugs impact caffeine clearance and half-life. This has been the topic of numerous earlier studies and reviews and will not be fully detailed here. The major interactions between caffeine and different families of drugs are summarized in Table 2.

The use of oral contraceptives, as detailed earlier, increases caffeine half-life. There is a marked interaction between caffeine and quinolone antibiotics and the likelihood of an interaction between caffeine and these drugs is the following: enoxacin $>$ ciproflaxin $=$ norfloxacin $>$ ofloxacin = lomefloxacin (Fuhr et al., 1992; Kinzig-Schippers et al., 1999; Granfors et al., 2004). These authors hence suggested to preferably prescribe non- or low interacting quinolones such as fleroxacin, ofloxacine, rufloxacin, tematofloxacin, and trovafloxacin, especially in heavy coffee drinkers. Most cardiovascular medications, such as antiarrhythmic drugs or calcium antagonists, tend to decrease caffeine elimination by 20\%-50\% (Joeres et al., 1987; Soto et al., 1994; Carrillo and Benitez, 2000).

A clear interaction was reported between the selective serotonin reuptake inhibitor fluvoxamine (50 and $100 \mathrm{mg} /$ day), used to treat depressive symptoms, and caffeine (200 mg orally) in healthy humans, leading to decreased total clearance of caffeine from 107 to $21 \mathrm{ml} / \mathrm{min}$ and increased caffeine half-life from 5 to 31 hours (Jeppesen et al., 1996). Sometimes, coadministration of caffeine and fluvoxamine have led to plasma caffeine concentrations increased to such an extent that it has been advised to suggest caffeine restriction in patients on fluvoxamine therapy (Culm-Merdek et al., 2005). Caffeine in daily doses of $400-1000 \mathrm{mg}$ inhibits the metabolism of another antidepressant, clozapine, but usually it is of minor clinical relevance. However, some patients appear to be more sensitive to the interaction, probably because of genetic factors (Raaska et al., 2004). Other antidepressants, such as venlafaxine; drugs used in anxiety disorders, such as alprazolam; the hypnotic zolpidem; the anticonvulsant drug trimethadione; and the vigilance medication armodafinil did not significantly change the pharmacokinetics of caffeine and its metabolites (Amchin et al., 1999; Schmider et al., 1999; Cysneiros et al., 2007; Darwish et al., 2008). Only psychoactive substances like tryptamine derivatives and the antipsychotic olanzapine slightly reduce caffeine clearance. Nineteen tryptamine-derived new psychoactive substances were tested recently. The results vary with the type of molecule, but the CYP inhibition by these substances might be clinically relevant and needs to be explored further in clinical studies (Dinger et al., 2016).

Some research has been devoted to the potential interaction between psychostimulants and caffeine. Similar to caffeine, a large number of psychiatric medications including antidepressants, antipsychotics, mood stabilizers, antianxiety, and sedative agents, are primarily metabolized by CYP1A2, which increases the possibility that caffeine consumed with these drugs may increase concentrations of nonmetabolized psychiatric medication to potentially toxic levels in both plasma 
TABLE 2

Drugs that influence caffeine pharmacokinetics

Data according to Soto et al. (1994), Amchin et al. (1999), Schmider et al. (1999), Carrillo and Benitez (2000 and references therein), Granfors et al. (2004), Culm-Merdek et al. (2005), Backman et al. (2006), Cysneiros et al. (2007), Darwish et al. (2008), Dinger et al. (2016), Yamazachi et al. (2017).

\begin{tabular}{|c|c|c|}
\hline Drug Class & Name & Effect on Caffeine Half-Life \\
\hline Oral contraceptives & All & About $+40 \%$ \\
\hline \multirow[t]{15}{*}{ Quinolone antibiotics } & Ami- and difloxacin & $+21 \%$ \\
\hline & Ciproflacin & $+70 \%$ \\
\hline & Enoxacin & $+75 \%$ \\
\hline & Fleroxacin & No effect \\
\hline & Grepafloxacin & $+50 \%$ \\
\hline & Lomeflaxin & $+23 \%$ \\
\hline & Nalidixic acid & $+67 \%$ \\
\hline & Norfloxacin & $+35 \%$ \\
\hline & Ofloxacin & No effect \\
\hline & Pefloxacin & $+22-47 \%$ \\
\hline & Pipemidic acid & $+59 \%$ \\
\hline & Rufloxacin & No effect \\
\hline & Temafloxacin & No effect \\
\hline & Tosufloxacin & $+34 \%$ \\
\hline & Trovafloxacin & No effect \\
\hline \multirow{7}{*}{ Cardiovascular drugs } & Mexiletine (anti-arrhythmic) & $+30 \%-50 \%$ \\
\hline & Diltiazem (calcium antagonist) & $+22 \%$ \\
\hline & Verapamil (calcium antagonist) & $+20 \%$ \\
\hline & Propafenone (anti-arrhythmic) & Increase \\
\hline & Propranolol (beta-blocker) & Increase \\
\hline & Triamterene (diuretic) & Increase \\
\hline & Warfarin (anticoagulant) & Increase \\
\hline \multirow[t]{9}{*}{ CNS drugs } & Clozapine (antidepressant) & Variable, up to $+26 \%$ \\
\hline & Fluvoxamine (antidepressant) & $-80 \%$; decreases caffeine half-life by sixfold \\
\hline & $\begin{array}{l}\text { Venlafaxine (antidepressant, } \\
\text { serotonin-norepinephrine reuptake } \\
\text { inhibitor (SNRI) }\end{array}$ & No significant effect \\
\hline & Alprazolam (anti-anxiety) & No significant effect \\
\hline & $\begin{array}{l}\text { Olanzapine (antipsychotic) (Shirley } \\
\text { et al. 2003) }\end{array}$ & Slows clearance, interindividual variability \\
\hline & Tryptamine derivatives (psychoactive) & Slows caffeine clearance to various degrees \\
\hline & Armodafinil (wakefulness promoting) & No significant effect \\
\hline & Tacrine (cholinesterase inhibitor) & Slows slightly clearance \\
\hline & Zolpidem (Hypnotic) & No significant effect \\
\hline \multirow[t]{2}{*}{ Anti-inflammatory drugs } & Idrocilamide & Half-life increased up to $63 \mathrm{~h}$ \\
\hline & Rofecoxib & Decreased clearance \\
\hline \multirow[t]{4}{*}{ Antifungal medication } & Fluconazole & $+25 \%$ \\
\hline & Isavuconazole & No effect \\
\hline & Ketoconazole & $+11 \%$ \\
\hline & Terbinafine & $+21 \%$ \\
\hline \multirow{5}{*}{ Proton pump inhibitors } & Cimetidine & $-31 \%$ \\
\hline & Lansoprazole & No effect \\
\hline & Omeprazole & $-41 \%$ \\
\hline & Pantoprazole & No effect \\
\hline & Ondansetron (anti-vomiting) & Slows clearance \\
\hline \multirow[t]{2}{*}{ Psoralens, anti-psoriasis and anti-eczema drugs } & Methoxsalen & $-70 \%$ \\
\hline & 5-Methoxypsoralen & $-31 \%$ \\
\hline \multirow[t]{2}{*}{ Bronchodilators } & Furafylline & Increases caffeine half-life up to 10 -fold \\
\hline & Theophylline & Slows caffeine clearance, twofold \\
\hline
\end{tabular}

and various body tissues (Donovan and DeVane, 2001). Students use stimulants, such as methylphenidate or $d$-amphetamine, to increase attention capabilities before examinations, and these drugs may be consumed along with caffeine. The combination of methamphetamine, $d$-amphetamine, ephedrine, and methylphenidate with caffeine has potential cardiovascular and CNS excitatory consequences. As an example, an adverse interaction between caffeine and the substituted amphetamine, 3,4-methylenedioxymethamphetamine (MDMA, "ecstasy") has been described. Caffeine strongly potentiates the acute toxicity of MDMA in rats, increasing body temperature, heart rate, and mortality. Caffeine worsens the long-term serotonergic neurotoxicity linked to MDMA. In sports, the combination of caffeine and ephedrine has become popular to enhance energy and performance. The combination of both substances during exercise increases circulating blood glucose, lactate, and epinephrine concentrations; stimulates pulmonary gas exchange; and increases heart rate. It also leads to a reduction in the rate of perceived exertion (for review, see Vanattou-Saïfoudine et al., 2012).

Idrocilamide, which is an anti-inflammatory and muscle relaxant drug, delays the elimination of caffeine, with a half-life reaching up to 63 hours that can be increased by ninefold in some cases. In people taking this type of medication, high coffee consumption can cause transient neurologic problems (Carrillo and Benitez, 2000). Rofecoxib, a nonsteroidal anti-inflammatory 
drug, slightly decreased caffeine clearance but has been withdrawn from the market over safety concerns. Among the triazole antifungal medications, isavuconazole does not affect CYP1A2-mediated metabolism (Yamazachi et al., 2016), whereas fluconazole and ketoconazole slightly but not significantly decrease caffeine clearance (Dinger et al., 2016). Drugs that are used to treat gastrointestinal problems, such as omeprazole and lansoprazole, that reduce the amount of acid in stomach and are prescribed in gastroesophageal reflux disease, do not affect caffeine metabolism, whereas cimetidine decreases half-life by $31 \%$. The antiemetic odansetron slightly decreases caffeine clearance (Carrillo and Benitez, 2000). Finally, and not surprisingly, bronchodilators such as furafylline and theophylline, which are also substrates for CYP1A2, interact with caffeine metabolism and slow caffeine clearance (Carrillo and Benitez, 2000).

b. Anticonvulsants. Caffeine is known as being proconvulsant, but the effects of the methylxanthine are partly paradoxical, because it acts as a proconvulsant after acute administration but is no longer proconvulsant when administered chronically (for review, see Nehlig and Fredholm, 2004). However, considering that most patients with epilepsy are under antiepileptic drugs (AEDs), the potential interaction between caffeine and AEDs on the expression of the disease is regularly questioned. The proconvulsant effects of methylxanthines are mainly due to their antagonism at adenosine $\mathrm{A}_{1}$ receptors (Moraidis and Bingmann, 1994). The major interactions between caffeine and anticonvulsants are summarized in Table 3.
Carbamazepine (CBZ) is a very frequently prescribed AED, and this drug has been associated with immune thrombocytopenia and neutropenia/agranulocytosis (Curtis, 2014a,b). Therefore, a potential interaction between caffeine ingestion and the circulating level of CBZ might be a concern. Approaches in rats and mice have shown that both acute and chronic caffeine treatment dose-dependently decrease the antiepileptic efficacy of CBZ without affecting the plasma level of the AED, which is in favor of pharmacodynamic interaction between the two drugs (Czuczwar et al., 1990; Gasior et al., 1996). A small human study on six volunteers reported that the half-life of CBZ was increased twofold and bioavailability reduced by $32 \%$ (Vaz et al., 1998).

Likewise, caffeine reduces the anticonvulsant properties of phenobarbital, phenytoin, sodium valproate, and diphenylhydantoin against maximal electroshock seizures in mice (Wlaź et al., 1992; Jankiewicz et al., 2007) and of ethosuximide against pentylenetetrazolinduced seizures in mice (Luszczki et al., 2006). The coingestion of caffeine along with clobazam or clonazepam did not appear to affect significantly the AED potency (Vaz et al., 1998; Luszczki et al., 2006; Walzer et al., 2012). Concerning the more recently marketed AEDs, acute and chronic caffeine decreased the anticonvulsant potential of gabapentin and topiramate, but this was not the case for lamotrigine, felbamate, oxcarbazepine, and tiagabine (Gasior et al., 1998; Jankiewicz et al., 2007; Chrościńska-Krawczyk et al., 2009, 2016). The lack of interaction with caffeine of some members of this new generation of AEDs might be related to the development of different mechanisms of action compared with the first generation AEDs, such as

TABLE 3

Interactions between caffeine and antiepileptic drugs (AEDs)

Data according to Czuczwar et al. (1990), Wlaz et al. (1992), Gasior et al. (1996, 1998), Vaz et al. (1998), Zuchora et al. (2005), Luszczki et al. (2006), Jankiewicz et al. (2007), Chrościńska-Krawczyk et al. (2009, 2016), Walzer et al. (2012).

\begin{tabular}{|c|c|c|}
\hline Anticonvulsant & Species & Type of Interaction \\
\hline \multicolumn{3}{|l|}{ Classic AEDs } \\
\hline Carbamazepine & $\begin{array}{l}\text { Rats, } \\
\text { mice }\end{array}$ & Acute and chronic caffeine dose-dependently decrease efficacy \\
\hline Carbamazepine & Humans & Increases half-life by twofold; decreases bioavailability by $32 \%$ \\
\hline Clobazam & Humans & $\begin{array}{l}\text { No significant action on clobazam pharmacokinetics } \\
\text { No interactions between clobazam and valproate or lamotrigine }\end{array}$ \\
\hline Clonazepam & Rats & No significant effect \\
\hline Diazepam & Mice & Decrease in efficacy \\
\hline Diphenylhydantoin & Mice & Decrease in efficacy \\
\hline Ethosuximide & Rats & Decrease in efficacy \\
\hline \multirow[t]{2}{*}{ Phenobarbital } & Rats & No significant effect \\
\hline & Mice & Decrease in efficacy \\
\hline Phenytoin & Mice & Decrease in efficacy \\
\hline \multirow[t]{2}{*}{ Valproate } & Rats & No significant effect \\
\hline & Mice & Decrease in efficacy \\
\hline \multicolumn{3}{|l|}{$\begin{array}{l}\text { Second generation } \\
\text { AEDs }\end{array}$} \\
\hline Felbamate & Mice & $\begin{array}{l}\text { No significant effect, decreased efficacy only at very high doses } \\
\quad(100-160 \mathrm{mg} / \mathrm{kg} \text { caffeine })\end{array}$ \\
\hline Gabapentin & Mice & Decrease in efficacy \\
\hline Lamotrigine & Mice & No significant interaction \\
\hline Oxcarbazepine & Mice & No significant interaction \\
\hline Tiagabine & Mice & No significant interaction \\
\hline Topiramate & Mice & Decrease in efficacy \\
\hline
\end{tabular}


the inhibition $N, P / Q$, and R-calcium currents for lamotrigine and oxcarbazepine, which is not shared by first generation AEDs or topiramate (Perucca, 2005). In addition, it has been suggested that the anticonvulsant potential of diazepam, phenobarbital, and valproate might be mediated, at least in part, by an action at adenosine $A_{1}$ receptors. Hence, ingestion of caffeine, especially high levels, might reduce its anticonvulsant efficacy, mainly in patients with seizures related to the disorders of the mitochondrial respiratory chain function caused by mutations (Zuchora et al., 2005). It is, however, critical to notice that the vast majority of these data have been obtained on animals, and human data are not available for most of the commercially prescribed AEDs. In addition, in most studies, the concentrations of caffeine used were high, often at least $20 \mathrm{mg} / \mathrm{kg}$ caffeine and up to $200 \mathrm{mg} / \mathrm{kg}$, which would represent 20-200 cups of coffee in one sitting in rats and about twofold less in mice. At the moment, there are no data available with reasonable amounts of caffeine in a more "human-like" paradigm, adding low quantities of caffeine to drinking water of the animals (usually 0.3 or $1.0 \mathrm{~g} / \mathrm{l})$.

c. Traditional Chinese and Asian medication. Among traditional Chinese medicine, the effects of sodium tanshinone IIA sulfonate, a water-soluble derivative of the Chinese medicine Danshen, were tested in healthy volunteers. By 6 hours, the activity of CYP1A2 increased by $41 \%$ (Chen et al., 2009a). On the contrary, St. John's wort (Esbericum capsules; $240 \mathrm{mg} /$ day of extract, $3.5 \mathrm{mg}$ hyperforin) given for depression treatment mainly induces CYP3A, which is not primarily involved in caffeine metabolism (Whitten et al., 2006), but does not affect the activity of CYP1A2 and hence caffeine metabolism (Arold et al., 2005). This is also true in elderly patients (Gurley et al., 2005a). Other traditional treatments contain mixtures of substances. In the case of Seijo-bofu-to, a traditional medicine used to treat acne in Asia, 12 herbal components are found, including Angelica dahurica root, which appears to inhibit by $33 \%$ the activity of CYP1A2 (Saruwatari et al., 2014). The Angelica dahurica root contains coumarin derivatives that strongly inhibit CYP1A1 and CYP1A2 as well as CYP2A6 (Tang and Eisenbrand, 2011 and references therein). The Evodia rutaecarpa prescription (Wu-Chu-Yu-Tang in Chinese or Goshuyu-to in Japanese Kampo medicine) is traditionally used to treat migraine and vomiting. It contains four herbs, Evodiae fructus, Ginseng radix, Zingiber rhizoma, and Zizyphi fructus. Evodia rutaecarpa extract and the herbal preparation Wu-Chu-Yu-Tang act as selective and potent inducers of CYP1A1, CYP1A2, and CYP1B1 (Tang and Eisenbrand, 2011 and references therein). Evodia rutaecarpa alone (Wu-Chu-Yu) as well as in the previous combination was reported to significantly decrease the level of theophylline given intravenously to rats at a low dosage $(2 \mathrm{mg} / \mathrm{kg})$ as the result of the metabolic induction of the methylxanthine (Jan et al., 2005). This preparation increases by about $40 \%$ the excretion ratio of caffeine in bile (Tsai et al., 2005). American and Asian ginseng extracts do not appear to induce hepatic P450 enzymes such as CYP2B1, CYP3A2, or CYP1A2 in adult rats in vivo and primary cultures or rat hepatocytes (Qi et al., 2011 and references therein). Among other herbal supplements that interact with P450 metabolized compounds, Echinacea purpurea was shown to have no effect on CYP2D6 while inducing very weak to modest inhibition of CYP2C9, modest inhibition of CYP1A2, and little induction of hepatic CYP3A4. The exposure to drugs like theophylline together with Echinacea purpurea, used for its powerful anti-inflammatory properties mainly in the common cold and mild diseases of the upper respiratory tract, might be increased marginally in some subjects but without apparent clinical significance (Hermann and von Richter, 2012 and references therein). In another study, no significant interaction was reported between herb supplements containing Citrus aurantium (sedative, anxiolytic, and hypotensive), Echinacea purpurea, milk thistle (Silybum marianum with hepatoprotective properties), or saw palmetto (Serenoa repens used in benign prostate hyperplasia), extracts which appear to pose a minimal risk for cytochrome P450-mediated potential herb-drug interactions in humans (Gurley et al., 2004). The interaction of herbal supplements with drugs appears to be quite complex and not fully understood at this point. Some herbs inhibit or antagonize drugs, whereas others act as agonists or synergists. In some cases, the interaction is more complex, showing a bimodal mode of action consisting of both antagonism and synergism (Posadzki et al., 2013 and references therein). Panax ginseng statistically significantly inhibits CYP2D6, but the effect (about 7\%) is not clinically relevant. None of the supplements tested appeared to affect CYP1A2 activity.

The interaction of Gingko biloba extract (10 or $100 \mathrm{mg} / \mathrm{kg}$ ) given for 5 days before theophylline $(10 \mathrm{mg} / \mathrm{kg})$ was tested in rats. The pretreatment of rats with the Gingko biloba extract increased theophylline clearance by $30 \%$ (low dose extract) or 70\% (high dose extract) reflecting that Gingko biloba extract increases CYP1A2 metabolic activity and theophylline clearance in rats (Tang et al., 2007). However, these data need replication because the dose of theophylline administered is too high to be translated to the human situation.

Andrographis paniculata extract, also called "king of bitters" because of its taste, and its major component, andrographolide has anti-inflammatory, antimicrobial, antiviral, and proimmune properties. It is currently used in cancer, Type 2 diabetes, and hepatitis. When given to rats during 3 days before a low dose of theophylline ( $1 \mathrm{mg} / \mathrm{kg})$, the two compounds significantly increased theophylline clearance. However, at a higher 
dose of theophylline $(5 \mathrm{mg} / \mathrm{kg})$, the methylxanthine accumulated in rats pretreated with Andrographis paniculata extract. This suggests an interaction of other herbal components contained in the extract with a high dose of theophylline (Chien et al., 2010).

In addition to the previously listed interactions between herbal supplements and caffeine, drug interactions related to numerous herbal supplements have been extensively reviewed recently (Tsai et al., 2012 and references therein). Among herbal supplements tested in humans, goldenseal (Hydrastis canadensis), used to prevent common colds and upper respiratory tract infections, strongly inhibits CYP2D6 and CYP3A4/5 activity in vivo. Kava kava (Piper methysticum), which displays sedative and anxiolytic properties, inhibits CYP2E1. Valerian (Valeriana officinalis) has sedativehypnotic and anxiolytic properties, but does not affect the activity of any CYP isoform. Finally, black cohosh (Cimicifuga racemosa) that alleviates menopausal symptoms and premenstrual syndrome interacts with CYP2D6 substrates. Thus all these supplements have a potential to interact with caffeine metabolism (Gurley et al., 2005b).

2. Influence of Caffeine on the Effects of Some Medications. When co-ingested with coffee, part of the phenothiazines that are antipsychotic medications is precipitated by coffee, thus decreasing their intestinal absorption (Roncucci et al., 1982). Likewise the simultaneous ingestion of coffee and ketoprofen, a nonsteroidal anti-inflammatory drug, should be avoided because of its interaction with renal prostaglandins, leading to the risk of decreasing urinary volume and forming precipitates (Nada, 1991). Caffeine does not modify the action of diuretics such as acetazolamide and furosemide (Delbeke and Debackere, 1988).

Consumption of coffee modestly increases the clearance of antipyrine by $1.4 \%$ per cup per day (Loft et al., 1988). Caffeine protects the liver against the toxicity of acetaminophen, assessed in rats and mice (Lee et al., 1991), and protects against the cytotoxicity and lowering of cell growth in culture of the intercalating drug novantrone (mixanthrone), an antineoplastic medication used in the treatment of prostate and other cancers (Traganos et al., 1991).

The anti-inflammatory drug methotrexate is commonly used to treat rheumatic arthritis. The adenosine $\mathrm{A}_{1}, \mathrm{~A}_{2 \mathrm{~A}}$, and $\mathrm{A}_{2 \mathrm{~B}}$ antagonist theophylline was shown in an animal model to markedly reverse the attenuating effects of methotrexate on arthritis symptoms. The kinetics of both drugs in interaction were not studied but it clearly appears that the effect is strong and that patients treated with methotrexate should avoid consuming caffeine (Montesinos et al., 2000).

Several interactions between caffeine and steroid function and effects have also been reported. It is known that caffeine increases the level of glucocorticoids that intervene in the regulation of metabolism, response to stress, and immune function. In human adrenocortical cells in culture, caffeine revealed a direct effect on the production of steroids but also a possible action via an inheritable epigenetic mechanism (Ping et al., 2012). In an in vivo study, caffeine intake of 300 or $600 \mathrm{mg}$ divided in three doses taken at 9:00 AM, 1:00 PM, and 6:00 PM caused a significant increase in cortisol release over the first day following 5 days of abstinence. This response progressively decreased with regular caffeine intake, but, although being diminished, it is still present after 5 days exposure in men and women, indicating partial tolerance (Lovallo et al., 2005). On the same line, MacKenzie et al. (2007) reported that $200 \mathrm{mg}$ of caffeine twice daily no longer had effects on cortisol levels after 7 days of administration. The increase in cortisol occurs 90 minutes after caffeine intake at 09:00 AM but not at 3:00 PM (Rieth et al., 2016). Most studies found no effect of caffeine consumption for 7 days (MacKenzie et al., 2007) or 4 or 8 weeks (Wedick et al., 2012). Only one study found a significant increase in DHEA at 9:00 AM after caffeine, but only in caffeine users (Rieth et al., 2016). Recently, a functional modulation of glucocorticoid receptors transcriptional activity and nuclear localization by adenosine $\mathrm{A}_{2 \mathrm{~A}}$ receptors has been described. This interaction impacts glucocorticoid receptor-mediated effects on synaptic plasticity, and the blockade of adenosine $A_{2 A}$ receptors by caffeine counteracts the negative effects linked to glucocorticoid receptor function and activation, and this is particularly relevant during stress situations and aging. Whether this interaction also occurs at the level of the immune response, metabolic regulation and other functions remains to be explored (Batalha et al., 2016).

In addition to its effects on cortisol levels, acute caffeine intake has been shown to totally impair the dexamethasone prevention test in normal individuals. As mentioned above, chronic exposure reduces the cortisol response to caffeine, and it was reported that regular caffeine consumption does not appear to dysregulate significantly the hypothalamic-pituitary-adrenal axis in severely depressed patients, probably because of the development of tolerance (Lee et al., 1988).

The brain microglial immune cells are responsive to glucocorticoids and morphologically altered in stressrelated disorders. These cells are regulated by adenosine $\mathrm{A}_{2 \mathrm{~A}}$ receptors, which also influence the pathophysiology of anxiety. It was reported recently that prenatal exposure to dexamethasone leads to sex-specific remodeling of microglial cell processes in the prefrontal cortex. In males, the processes that undergo hyperramification are longer, whereas in females, the number and length of microglial processes are diminished. Chronic treatment with a selective adenosine $\mathrm{A}_{2 \mathrm{~A}}$ receptor antagonist leads to a sex-specific response. It allowed partial prevention of the alterations in microglial processes and anxiety behavior in males, but not in females (Caetano et al., 2017). 


\section{The Role of Tolerance in the Variability of Caffeine Consumption}

The chronic consumption of caffeine might also be influenced by the development of tolerance. Tolerance to a drug refers to an acquired change in the response of a subject repeatedly exposed to the substance and can be considered in two ways. First, tolerance might indicate that the dose required to reach the desired positive/reinforcing effects increases over time, thus leading people to gradually consume higher amounts of the drug. Second, tolerance to some of the aversive effects of the drug may occur, hence leading people to consume larger doses over time.

In humans, tolerance to the behavioral effects of caffeine is incomplete and of low magnitude (Fredholm et al., 1999; Watson et al., 2002). This may reflect the interindividual differences in the susceptibility and tolerance to caffeine-related effects (Nehlig, 2004). In humans, daily caffeine consumption is regulated by each individual to reach a good balance between the desired positive effects (relaxation, alertness, attention, productivity, concentration, focus) and to avoid the potential negative effects (anxiety, irritability, nervousness, insomnia). This is well illustrated by the variations in the circadian pattern of coffee/caffeine consumption as reported by Smith (2002) and the recent survey performed by the Institute for Scientific Information on Coffee (ISIC), Expert Report (http://www.coffeeandhealth.org/ wp-content/uploads/2017/09/Coffee-in-the-Workplacereport-FINAL-250917.pdf). Individuals who drink coffee during working hours are most likely to drink coffee between 9 and 11 AM (59\%) with the exception of the Finnish population that prefers to consume coffee between 1 and 3 PM (57\%). This pattern of consumption reflects the time when people need to concentrate and be productive at work. Across all countries recently surveyed, there is a clear pattern of coffee consumption: peaking in the morning, followed by a slight rise at lunchtime (1-3 PM), and undergoing a gradual decrease during the rest of the afternoon when individuals try to avoid negative effects of caffeine on sleep (http://www. coffeeandhealth.org/wp-content/uploads/2017/09/Coffeein-the-Workplace-report-FINAL-250917.pdf; Smith, 2002). Likewise, caffeine consumption during weekends is lower than during working days.

Tolerance to some subjective effects of caffeine, namely anxiety, jitteriness/nervousness, activity/stimulation/ energy, and the potency of caffeine effects might occur (Evans and Griffiths, 1992). Tolerance to caffeine-induced alertness and wakefulness is debated (for review, see Nehlig, 2004). These effects are paralleled by the lack of tolerance of cerebral glucose metabolism and brain function to caffeine. As shown in rodents, the acute administration of a low dose of caffeine leads to similar metabolic increases whether the animals have been exposed for 15 days to daily chronic treatment of caffeine or saline.
This is mainly true in the areas mediating locomotor activity and the sleep-wake cycle that are especially sensitive to the effects of caffeine (Nehlig et al., 1986).

In humans, habitual daily coffee drinking does not clearly affect the consequences of caffeine exposure on total sleep time and the outcome of studies is somewhat inconsistent. Heavy consumers of caffeine might tend to experience more limited effects of caffeine on sleep, but tolerance is incomplete, in particular for the latency before falling asleep after caffeine consumption shortly before bedtime (Snel, 1993).

In humans, there is tolerance to peripheral actions of caffeine. This is the case for the effect of caffeine on blood pressure and heart rate, diuresis, plasma adrenaline and noradrenaline levels, and renin activity (for review, see Nehlig, 2004). Likewise, a regular exposure to caffeine could affect physical performance, leading to tolerance to the beneficial effects of caffeine in some studies (Beaumont et al., 2017) but not in other reports (Bell and McLellan, 2002).

The potential molecular mechanisms underlying the partial brain tolerance to caffeine have not been much studied. The reaction to a locomotor challenge induced by the acute injection of $7.5 \mathrm{mg} / \mathrm{kg}$ caffeine in rats receiving $0.3 \mathrm{~g} / \mathrm{l}$ caffeine in their drinking water for 14 days is subject to tolerance. This effect is not linked to the total level of active metabolites in the brain, which is not significantly altered, although the metabolism of caffeine appears to be increased in tolerant animals. The levels of adenosine $\mathrm{A}_{2 \mathrm{~A}}$ receptors and their corresponding mRNAs are downregulated in caffeine-tolerant animals in parts of the striatum, whereas the expression of adenosine $A_{1}$ receptor mRNA is increased in lateral amygdala (Svenningsson et al., 1999). This shows that regular caffeine exposure acts on the expression of some genes, but most of the molecular pathways underlying the effects of chronic caffeine exposure are still not well understood.

Thus, tolerance to some effects of caffeine will clearly participate to the fine tuning of caffeine consumption in the individuals. However, it appears that tolerance, at least at the central level, develops only for some specific pathways and at this point we still do not have a comprehensive view of how these specific effects might influence caffeine consumption. We also lack a mechanistic basis for the understanding of the molecular pathways underlying the development of tolerance. Finally, it is important to remember that caffeine is a psychostimulant that acts differently from many other ones and, in most instances, does not induce a dose escalation over time.

\section{Interindividual Differences Due to Genetic Factors}

Based on twin studies, the heritability of caffeinerelated traits and coffee consumption is estimated to 
range between 0.36 and 0.58 . Predisposition to consume caffeine appears to be highly specific and shares only limited common features with the use of other substances. Coffee consumption is affected by combined genetic and unique environmental factors, both playing an almost equally important role. However, the long-term stability of coffee consumption is considered to be affected primarily by additive genetic factors. Genetics are clearly involved in individual variability in caffeine consumption and in the direct effects of caffeine. This modulation occurs both at the pharmacodynamic and pharmacokinetic level and has been linked to the variability in response to caffeine (Laitala et al., 2008; Yang et al., 2010).

\section{A. Pharmacokinetic Regulation}

Table 4 summarizes most of the consequences of the polymorphisms at the level of the genes coding for the enzymes involved in caffeine metabolism on the possible regulation of daily caffeine consumption.

1. Cytochrome P450, Isozyme 1A2 (CYP1A2), and CYP2A6. The 1A2 isozyme of cytochrome $\mathrm{P} 450$ (CYP1A2) is only present in the liver and represents around $15 \%$ of the total cytochromes. CYP1A2 is responsible for over $90 \%$ of caffeine clearance. The large interindividual variability in the activity of CY1A2 influences the disposition of caffeine. As shown in Fig. 1 , CY1A2 is involved in many pathways of caffeine, theophylline, and paraxanthine degradation.

The variability of CYP1A2 activity is largely explained by a gene polymorphism. An $\mathrm{A}$ to $\mathrm{C}$ substitution at position 163 (rs762551) in the CYP1A2 gene decreases enzyme inducibility as reflected by plasma or urinary caffeine-to-metabolite ratios after caffeine intake (Sachse et al., 1999). The distribution of CYP1A2 activity in the population appears to be bimodal with the $\mathrm{C}$ variant being associated with slowing down of caffeine clearance. Carriers of the $\mathrm{C}$ allele, $54 \%$ of the population $(163 \mathrm{~A} / \mathrm{C}$ and $163 \mathrm{C} / \mathrm{C}$ genotypes; CYP1A2*1F), metabolize caffeine more slowly than individuals homozygous for the 163A/A allele (CYP1A2*1A) who are considered rapid caffeine metabolizers and represent $46 \%$ of the population (Sachse et al., 1999; Cornelis et al., 2006). According to studies performed in populations from Arkansas, Italy, and China, CYP1A2 activity is not normally distributed and appears to be trimodal, with slow (12\%-13\%), intermediate $(51 \%-67 \%)$, and rapid phenotypes (20\%-37\%) (Butler et al., 1992). Slow and intermediate metabolizers represent about $50 \%$ of Caucasians, but are less frequently encountered in Japanese subjects (Landi et al., 1999).

There is also a polymorphism at the level of CYP2A6, another liver enzyme involved in the metabolism of paraxanthine to 1,7-dimethyluric acid (Fig. 1). At this point, the studies remain limited to a few population samples. By using a caffeine probe, genotyping for CYP2A $6 * 1 \mathrm{~B}, * 1 \times 2, * 4, * 5, * 7, * 8, * 9, * 10, * 18$, and *19 alleles was performed in a Swedish and Korean population. Ethnicity and CYP2A6 genotype are predictors of CYP2A6 activity and the CYP2A6 genotype distribution and enzyme activity is significantly different in Swedes and Koreans, but the activity of this isozyme is not influenced by sex, age, smoking, or oral contraceptive use. CYP2A6 activity is higher in Swedes than in Koreans, even among carriers of rapid genotypes; $3.2 \%$ Swedes and $18.8 \%$ Koreans are slow metabolizers. In Swedes, functional CYP2A6 alleles and rapid genotypes are more frequently found, whereas defective alleles and slow genotypes are more frequent in Koreans (Djordjevic et al., 2013). According to another source, the distribution of CYP2A6 activity in the Nigerian population is trimodal, whereas that of CYP1A2 is bimodal (Adehin and Bolaji, 2015a).

A couple of studies have looked at functional consequences of CYP1A2 polymorphism. An elevated consumption of caffeine seems to be a major inducer of a higher activity of CYP1A2 activity (Urry et al., 2016). Women consuming $\geq 300 \mathrm{mg}$ caffeine daily and are fast metabolizers of caffeine (carrying the CYP1A2 C164A phenotype) may be at increased risk for giving birth to infants with decreased birth size according to a

TABLE 4

Pharmacokinetic regulation of caffeine consumption linked to genetic polymorphism

More details can be found in the text.

\begin{tabular}{|c|c|c|c|c|}
\hline Enzyme & Biologic Role & Clinical Relevance & Replication & $\begin{array}{c}\text { Location in } \\
\text { Text }\end{array}$ \\
\hline CYP1A1 & $\begin{array}{l}\text { CYP1A1 metabolizes } \\
\text { - caffeine to paraxanthine, theobromine and } \\
\text { 1,3,7-TMU } \\
\text { - polycyclic aromatic hydrocarbons, which are } \\
\text { important constituents of coffee }\end{array}$ & Association with habitual caffeine consumption & Yes & IV.A.4 \\
\hline CYP1A2 & Major enzyme involved in liver caffeine metabolism & Association with habitual caffeine consumption & Yes & $\begin{array}{l}\text { IV.A. } 1 \\
\text { IV.A.4 }\end{array}$ \\
\hline CYP2A6 & Metabolism of paraxanthine to $1,7-\mathrm{DMU}$ & No clear link with consumption shown yet & Yes & IV.A.1 \\
\hline NAT2 & Metabolism of paraxanthine to AFMU & No clear link with consumption shown yet & Yes & IV.A.2 \\
\hline $\mathrm{XO}$ & Metabolism of 1-MX to $1-\mathrm{MU}$ & $\begin{array}{l}\text { 1MU:1MX ratio used following caffeine } \\
\text { administration as a pharmacodynamic measure of } \\
\text { drug effect on XO activity }\end{array}$ & Yes & IV.A.3 \\
\hline
\end{tabular}

AFMU, 5-acetylamino-6-formylamino-3-methyluracil; CYP, cytochrome P450 followed by the number corresponding to each specific isoform; NAT2, N-acetyltransferase-2; $\mathrm{XO}$, xanthine oxidase; 1,3,7-TMU, 1,3,7-trimethyluric acid; 1,7-DMU, 1,7-dimethyluric acid; 1-MX, 1-methylxanthine; 1-MU, 1-methyluric acid. 
Japanese study (Sasaki et al., 2017). This association might help understanding the inconsistent effects observed on the fetus after caffeine consumption.

A pilot study reported a lack of influence of CYP1A2 polymorphism on ergogenic effects of caffeine. On the other hand, $31 \%$ of the C-allele carriers rated increased nervousness after caffeine (Salinero et al., 2017).

2. $N$-Acetyltransferase-2. Likewise, NAT2 is a key enzyme in caffeine metabolism and metabolizes the degradation of paraxanthine to 5-acetyl-amino-6formylamino-3-methyluracil, as shown in Fig. 1. The polymorphisms of the NAT2 gene show a typical bimodal distribution, with $47 \%$ fast acetylators and $53 \%$ slow acetylators in the Danish population. There is no sex-related difference in the percentage of slow acetylators (men, 58\% and women, 51\%) (Welfare et al., 2000). The distribution of NAT2 activity is influenced by ethnicity. The NAT2 fast acetylator genotype is more frequent in Koreans and Japanese (89\%), whereas the slow acetylator genotype is predominant in Swedes $(62 \%)$ and Serbs (55\%). NAT2 activity is also higher in Koreans than in Swedes (Saruwatari et al., 2002; Djordjevic et al., 2011, 2013).

One recent study looked at the potential health consequences of the association between caffeine consumption and the polymorphism of CYP1A2 and NAT2 governing the activity of both enzymes. They reported that subjects consuming large coffee and tea amounts and having slow CYP1A2 or NAT2 activity had the same risk of developing colorectal cancer as non/low coffee and tea consumers with a fast CYP1A2 or NAT2 activity. This suggests that caffeine metabolism does not influence the association between coffee/tea consumption and the risk of colorectal cancer (Dik et al., 2014).

3. Xanthine Oxidase. Xanthine oxidase (XO) is one of the two interconvertible forms of xanthine oxidoreductase and has been extensively studied because of its role in purine catabolism. The oxidation of 1-methylxanthine (1MX), a secondary metabolite of caffeine to 1-methyluric acid (1MU) is catalyzed exclusively by $\mathrm{XO}$, and the ratio of the metabolites excreted in the urine $[1 \mathrm{MU} /(1 \mathrm{MU}+1 \mathrm{MX})]$ is used as an index of the activity of the enzyme (Kalow and Tang, 1991a). In a Nigerian population, $\mathrm{XO}$ activity was reported to vary by a sevenfold factor. The enzyme activity was notably more elevated in $8 \%$ of the population, confirming the presence of a polymorphism of XO activity in Nigerians (Adehin and Bolaji, 2015b). XO activity was not significantly different between Swedes and Koreans. In Swedes, XO activity was higher in women than in men (Djordjevic et al., 2012).

4. Polymorphisms of Enzymes Metabolizing Caffeine and Their Consequences on Coffee/Caffeine Consumption. Several studies, including mainly genome-wide association studies (GWAS), explored the consequences of the polymorphisms and variable activities of the enzymes involved in caffeine metabolism on coffee/caffeine consumption. The studies were often performed considering CYP1A1, which metabolizes caffeine to paraxanthine, theobromine, and 1,3,7-TMU and, on the other hand, polycyclic aromatic hydrocarbons, which are important constituents of coffee. Studies often also concerned CYP1A2, which is involved in the primary metabolism of caffeine.

In addition to the enzymes involved in caffeine metabolism, several of these studies included the arylhydrocarbon receptor (AHR), which interacts with xenobiotics, such as polycyclic aryl hydrocarbons, flavonoids, and polyphenols present in roasted coffee. AHR is a cytosolic transcription factor that is usually inactive. After binding to various substances, AHR is translocated into the cell nucleus, leading to changes in gene transcription, such as transcription of CYP1A1 and CYP1A2.

A meta-analysis of 47,341 individuals of European ancestry, derived from five studies within the United States, was performed using directly genotyped and single nucleotide polymorphisms (2.5 million SNPs). Two sequence variants were found to be significantly associated with increased coffee consumption: rs2472297-T located between CYP1A1 and CYP1A2 at $15 \mathrm{q} 24\left(P=5.2 \times 10^{-14}\right)$ and $\mathrm{rs6968865-T}$ near AHR at $7 \mathrm{p} 21\left(P=2.4 \times 10^{-19}\right)$. An effect of $\sim 0.2$ cups a day per allele was observed for both SNPs (Cornelis et al., 2011). Heavy coffee consumers have higher CYP1A2 activity than those drinking less coffee (Tantcheva-Poor et al., 1999; Djordjevic et al., 2008), whereas low CYP1A2 activity (reduced N1-, N3-, and N7-demethylations) has been found more often in subjects with toxic symptoms linked to caffeine consumption (Carrillo and Benitez, 1996). Possibly rs2472297-T and rs6968865-T allow people to consume more coffee, because in these carriers clearance of caffeine is more effective as a result of higher CYP1A1 or CYP1A2 enzymatic activity, but this has still to be proven. The association of these SNPs with coffee consumption was found in smokers and nonsmokers (Sulem et al., 2011). Moreover these two SNPs linked to AHR and CYP1A1-CYP1A2 also associated with habitual caffeine consumption in a Costa Rican population, with age and smoking being important effect modifiers (Josse et al., 2012).

In a more recent study, Cornelis et al. (2015) identified eight loci, including six novel ones, with effect sizes per allele of $0.03-0.14$ cups per day. Six are located in or near genes possibly involved in caffeine pharmacokinetics, such as 4q22 (ABCG2 transporter), 7q11.23 (CYPOR, a membrane-bound oxidoreductase required for electron transfer from NADPH to all microsomal cytochrome $\mathrm{P} 450$ enzymes in the endoplasmic reticulum), 7p21 (near AHR), and 15q24 SNP (near CYP1A2) and pharmacodynamics, such as 11p13 (BDNF, brainderived neurotrophic factor) and 17q11.2 (the monoamine transporter SLC6A4). Two other ones map to 
2p24 (GCKR, glucokinase regulatory protein) and 17q11.2 genes (MLXIPL, transcription factor involved in the regulation of glycolysis and lipogenesis in the liver) that are involved in the regulation of metabolism, although their potential role in coffee intake is not yet clear. Loci near BDNF and SLC6A4 seem to impact directly on coffee/caffeine consumption via modulation of the acute stimulating and reinforcing properties of caffeine. BDNF belongs to the neurotrophin family, enhances synaptic transmission, and regulates neuronal proliferation and survival. The adenosine $\mathrm{A}_{2 \mathrm{~A}}$ receptors (ADORA2A) interact with $\mathrm{BDNF}$, are required for most of the synaptic actions of BDNF and regulate $\mathrm{BDNF}$ functions and levels in the brain (Sebastião et al., 2011). Other loci near AHR, CYP1A2, CYPOR, and ABCG2 adjust caffeine metabolism and hence affect the levels of the methylxanthine. The potency of the latter associations with coffee intake underlies the prominent role of caffeine metabolism in coffee drinking behavior. In addition, the glucokinase regulatory protein (GCKR) and the enzyme glucokinase regulate glucose sensing in the brain (Alvarez et al., 2002), possibly influencing cerebral pathways affected by various coffee components. Glucokinase is a hexokinase isozyme facilitating phosphorylation of glucose to glucose-6-phosphate, predominantly in the liver. Glucose-6-phosphate is a substrate for both glycolysis and glycogen synthesis. The activity of this enzyme fluctuates with available glucose and can be increased or decreased rapidly under the action of GKRP, which is influenced by available glucose around the hepatocytes. This rapid regulation might reflect the known ergogenic properties of caffeine (Goldstein et al., 2010). Alleles near GCKR, MLXIPL, BDNF, and CYP1A2 that were associated with higher coffee intake have previously been associated with various parameters, such as smoking initiation, higher body fat, levels of insulin and glucose during fasting, lower blood pressure, and better profiles of lipids, inflammatory molecules, and liver enzymes. However, how these variables relate to coffee intake has not yet been clearly established. These genetic findings among the European and AfricanAmerican ancestry adult population favor the role of metabolic and neurologic mechanisms linked to caffeine in coffee consumption. Individuals adjust their coffee intake habits to favor reinforcing feelings at the expense of perceived negative effects, both being influenced by genetic variability. Pharmacokinetic variations (caffeine metabolism is affected by the polymorphisms of CYPA12 but also of other genes like AHR, POR, and ABCG2) act on the circulating levels of caffeine and pharmacodynamic properties of caffeine (loci near BDNF and SLC6A4) influence reinforcing effects of the methylxanthine. They are all in relation with the genetic trait to consume caffeine/coffee, but it seems that caffeine metabolism plays the most critical role in influencing coffee drinking behavior (Cornelis et al., 2015).
In another recent study concentrating on the genetic variability at CYP1A2 (rs2470893; rs2472297; rs2472299) and AHR genes (rs4410790; rs6968865), caffeine intake allele score at the level of rs4410790 (AHR) and rs2470893 (CYP12A) was associated with a $42 \%$ higher coffee intake, indicating the cooperative action of both loci (Nordestgaard and Nordestgaard, 2016). The association between coffee consumption and genetic variability at CYP1A2 and AHR genes is of particular interest. Indeed, CYP1A2 is the enzyme responsible for over $90 \%$ of caffeine metabolism, but is also involved in various other drug metabolisms, as mentioned earlier. AHR interacts with xenobiotics, such as dioxin and the polycyclic aryl hydrocarbons present in roasted coffee, and induces transcription of CYP1A1 and CYP1A2. Coffee has been reported to activate AHR and CYP1A2 in cultured cells (Ishikawa et al., 2014), which indicates that the constituents of coffee other than caffeine also regulate coffee intake, and their effect will need to be studied in more detail to get a whole picture of the regulation of coffee versus caffeine consumption.

On the same line, more recently Cornelis et al. (2016) conducted a GWAS on the association between SNPs and the plasma levels of the various methylxanthines in 9876 subjects of European descent from six populationbased studies. Higher plasma caffeine and lower plasma paraxanthine/caffeine levels reflecting slower caffeine metabolism associated with variants at $7 \mathrm{p} 21$ (near AHR) and 15q24 (near CYP1A2). These variants were previously associated with reduced consumption of coffee/caffeine in the GWAS. Higher plasma paraxanthine/caffeine levels, reflecting slow paraxanthine metabolism associated with variants at 19q13.2 (near CYP2A6 that metabolizes paraxanthine) and were also associated with lower coffee consumption. Other variants located at 2p24 (GCKR), 4q22 (ABCG2), and $7 q 11.23$ (near CYPOR) have been associated with levels of coffee consumption in the GWAS and were only marginally associated with the levels of caffeine and its metabolites in plasma. These data are in favor of the critical modulatory role played by systemic caffeine levels in adjusting daily caffeine consumption to obtain the optimal stimulant and positive reinforcing effects of caffeine whenever needed.

A recent meta-analysis included 12 studies and looked at the association between habitual coffee intake and CYP1A2 rs762551 polymorphism that splits the population in AA (rapid caffeine metabolizers) and AC and CC genotypes (slow caffeine metabolizers). The analysis showed an association between the AA genotype and coffee consumption [OR $=1.13,95 \%$ confidence interval $(\mathrm{CI})=1.03-1.24 ; P=0.06]$. This association was found in men, individuals younger than 59 years, and Caucasians, but not in females, individuals older than 59 years, and Asians. This is the first study pointing out the weak association between the fast caffeine 
metabolizer profile and coffee intake in the Asian population, as well as the age- and sex-related variation. These specificities need to be further explored (Denden et al., 2016).

Recent population-based metabolomic studies of coffee confirmed the correlations between coffee/caffeine consumption previously reported but have also found other metabolites linked to the response of the individuals to coffee. Self-reported coffee/caffeine intake and circulating levels of caffeine are key factors in the adjustment of coffee/caffeine consumption by individuals. However, the persistence and magnitude of the effects are also influenced by interindividual variability in the physiologic response to the different coffee constituents. Hence, future studies will need to take into account these various aspects to better understand the long-term effects of coffee/caffeine consumption on the body and their interindividual variability (Cornelis, 2015).

5. Influence of CYP1A2 and Aryl-hydrocarbon Receptor Genetic Variability in Specific Responses to Coffee/Caffeine Consumption. Some studies have looked at the influence of this genetic variability on some aspects of human physiology.

The study of gene polymorphisms at the level of AHR (rs4410790; rs6968865) and CYP1A1/2 genes (rs2470893; rs2472297; rs2472299) did not show any association between the risk of cardiovascular disease and mortality from cardiovascular disease or all causes (Nordestgaard and Nordestgaard, 2016).

In a small sample of population (57 Type 2 diabetes and 146 control subjects), the activity of CYP1A2 and metabolism of caffeine was significantly higher in the Type 2 diabetes patients compared with controls. It is not established whether the higher CYP1A2 enzyme activity in patients is causally related to higher caffeine intake (Urry et al., 2016).

The polymorphism of the CYP1A2 enzyme (AA homozygous vs. C-allele carrier subjects) did not influence the ergogenic or side effects of the ingestion of $3 \mathrm{mg} / \mathrm{kg}$ caffeine before exercise (Salinero et al., 2017).

One single study looked at the association between caffeine intake during pregnancy and CYP1A2 and NAT2 polymorphisms. High CYP1A2 activity may increase the risk of spontaneous abortion at a daily ingestion of $300 \mathrm{mg}$ caffeine. It is unknown whether this effect is linked to the circulating level of caffeine. Concerning NAT2, the risk of spontaneous abortion and recurrent spontaneous abortion may be more elevated in slow acetylators (Signorello et al., 2001).

\section{B. Pharmacodynamic Regulation}

Caffeine intake varies widely as a function of both the country and individual. This variability might be partly linked to the fact that some persons experience side effects such as anxiety, tachycardia, nervousness after caffeine intake. Some studies on twins have shown the role of genetic factors (Luciano et al., 2005). Table 5 summarizes some of the consequences of the polymorphisms at the level of the genes coding for the adenosine A2A receptor (ADORA2A) and of one enzyme involved in the metabolism of adenosine, adenosine deaminase (ADA).

As developed above, the polymorphisms in genes related to caffeine metabolism may underlie to a large extent the variability in caffeine intake. However, other genes are also clearly involved. It has been shown that in amounts reached after the consumption of 1 to 2 cups of coffee, caffeine acts as an antagonist of the adenosine A2A receptors (ADORA2A), which plays a critical role in the stimulating and reinforcing properties of caffeine (Ledent et al., 1997; Huang et al., 2005). Indeed, ADORA2A knockout mice are less attracted by caffeine than their wild-type littermates (El Yacoubi et al., 2005). However, it is not known whether individuals with that genotype limit their habitual caffeine intake because of a similar type of adenosine $\mathrm{A}_{2 \mathrm{~A}}$ receptormediated effects. In this part, we will examine the potential impact of polymorphisms at the major target of caffeine action in the CNS, the ADORA2A, and try to understand how it may be associated with habitual caffeine consumption in the population.

There are eight most prevalent single nucleotide polymorphisms (SNPs) in a 25-kb stretch of the ADORA2A (rs5751862, rs5760405, New3, rs11704959, rs2298383, rs3761422, rs2267076, and rs5751876). The latter one, a C-to-T substitution at nucleotide position 1083 (rs5751876) (also referred to as 1976C $>\mathrm{T}$ ) has been repeatedly reported to be associated with different brain-related functions that will be reviewed later in this document. Interestingly, it is associated with the amount of coffee consumed (Cornelis et al., 2007).

Finally, a few other representative genes that are involved in caffeine effects and could influence coffee/ caffeine consumption will be mentioned.

1. Polymorphisms at the Adenosine A2A Receptor and Adenosine Deaminase Genes.

a. Anxiety and emotional and sensory processing. The development of anxiety disorders and panic disorder is considered to involve a complex interaction of genetic, neurotransmitter, and environmental factors. Several risk loci for panic disorder have been identified by linkage studies (Domschke and Deckert, 2012), and association studies have provided evidence that the $\mathrm{T}$ allele of a silent polymorphism (SNP rs5751876, T-to-C substitution at nucleotide 1976, former 1083) in exon 2 of the ADORA2A on chromosome $22 \mathrm{q} 11.23$ is associated with panic disorder (Deckert et al., 1998) and higher levels of anxiety in healthy subjects (Hohoff et al., 2010). In addition to the latter variant (1976T $>$ C), the rs2298383 variant ( $2592 \mathrm{C}>$ Tins) is also potentially involved in anxiety disorders and may in fact represent the true underlying causal variant (Hohoff et al., 2010). 
TABLE 5

Potential role of the polymorphisms of ADORA2A and adenosine deaminase genes in caffeine-related functions and caffeine consumption More details can be found in the text.

\begin{tabular}{|c|c|c|c|c|}
\hline Gene & Biologic Role & Clinical Relevance & Replication & $\begin{array}{l}\text { Location in } \\
\text { Text }\end{array}$ \\
\hline \multirow[t]{6}{*}{ ADORA2A } & Anxiety & $\begin{array}{l}\text { Modulation of anxiety levels in response to } \\
\text { caffeine intake }\end{array}$ & Yes & IV.B.1.a \\
\hline & Attention & $\begin{array}{l}\text { Influence on attentional processing and working } \\
\text { memory }\end{array}$ & Yes & IV.B.1.a \\
\hline & $\begin{array}{l}\text { Emotional processing } \\
\text { Maladaptive emotional processing } \\
\text { Impact on the selection of relevant early } \\
\text { information }\end{array}$ & Influence on startle reflex & Yes & IV.B.1.a \\
\hline & $\begin{array}{l}\text { Panic disorder } \\
\text { Agoraphobia }\end{array}$ & Extreme reactions to stressful situations & Yes & IV.B.1.a \\
\hline & $\begin{array}{l}\text { Sleep } \\
\text { Sleep latency } \\
\text { Modification of EEG sleep-linked } \\
\text { characteristics }\end{array}$ & Susceptibility to hyperarousal-induced insomnia & Yes & IV.B.1.b \\
\hline & Caffeine consumption & Carrying the 1976TT genotype decreases caffeine consumption & No & IV.B.1.c \\
\hline $\begin{array}{l}\text { Adenosine } \\
\text { deaminase }\end{array}$ & Sleep & $\begin{array}{l}\text { Role in sleep architecture and maintenance } \\
\text { Controls the frequency of awakenings }\end{array}$ & Yes & IV.B.1.b \\
\hline
\end{tabular}

The C-to-T substitution at nucleotide positions $1976 \mathrm{C}>\mathrm{T}$ and 2592Tins (rs2298383) in the ADORA2A gene is associated with caffeine-induced anxiety among nonhabitual caffeine consumers, and subjects homozygous for the two alleles experience greater anxiety after consuming $150 \mathrm{mg}$ caffeine (Alsene et al., 2003). However, although there is greater susceptibility to caffeine-induced anxiety, habitual caffeine intake is not lower in the 1976TT genotype group, and a reduced anxiety response is found in medium/high ( $\geq 40 \mathrm{mg} /$ day $)$ versus non/low consumers ( $<40 \mathrm{mg} /$ day), irrespective of the genotype (Rogers et al., 2010).

Very early information processing can be evaluated by the prepulse inhibition paradigm (PPI) of the acoustic startle reflex. This reaction might represent a filter mechanism to protect the body from information overload (Braff et al., 2001). PPI is a neurologic phenomenon in which a weaker prestimulus (prepulse) given to warn the organism reduces the startle reaction of an organism to a subsequent strong startling stimulus (pulse). In ADORA2A 1976TT homozygous risk genotype carriers, PPI is impaired in females compared with males, whereas no significant sex differences were observed in the ADORA2A 1976CC/CT non-risk genotype or placebo group. Only high anxiety sensitive groups develop a significantly impaired prepulse facilitation due to caffeine. Thus female ADORA2A 1976TT homozygotes seem to have an impaired ability to process selectively very early information in response to caffeine, providing evidence for the participation of the adenosinergic system in anxiety (Gajewska et al., 2013) and hence for a potential limitation of caffeine consumption in these subgroups.

A recent fMRI study reported increased connectivity in the fronto-insular network likely reflecting enhanced processing of interoceptive information. This might underlie deviant attentional processing in ADORA2A risk genotype carriers (Geiger et al., 2016). In
199 healthy control subjects, the study of two polymorphisms of the ADORA2A gene, rs5751876 (1976T $>$ C) and rs2298383, showed a differential modulation of preattentive sensory memory processes. The visual stimulus information available initially is more efficient in the homozygous rare genotype groups, whereas the transfer of information into working memory and duration of iconic memory are compromised in the same subjects. This modulation has been attributed to increased adenosine $A_{2 A}$ receptor interaction at the level of glutamatergic neurotransmission in the striatum (Beste et al., 2012).

The effect of $300 \mathrm{mg}$ caffeine versus placebo was tested on the emotion-potentiated startle reflex in individuals stratified for the ADORA2A 1976T $>$ C polymorphism. The test consisted in the presentation of unpleasant, neutral, and pleasant pictures from the International Affective Picture System. In addition to the expected main effect of picture category (highest startle amplitude for unpleasant, lowest for pleasant pictures) across all ADORA2A 1976T $>$ C genotype and treatment (caffeine vs. placebo) groups, the authors observed that in ADORA2A 1976TT risk genotype carriers, highest startle magnitudes occurred after caffeine administration in response to unpleasant pictures, especially in women. This shows a complex regulation and possible sex-specific regulation of anxiety, with genetic and biochemical factors interacting and increasing the risk of maladaptive emotional processing, potentially leading to anxiety disorders (Domschke and Deckert, 2012).

The known variations in the ADORA2A, catechol-Omethyl-transferase, and norepinephrine transporter (NET) genes in vulnerability to panic disorder have been explored during venipuncture, a naturalistic trigger of blood-injury phobia, an anxiety disorder whose heritability is even higher than the panic disorder. Patients homozygous for the ADORA2 1976T allele 
compared with patients carrying at least one 1976C allele exhibited a significantly increased respiratory rate and elevated systolic and diastolic blood pressure and respiratory minute volume. Catechol-O-methyltransferase or norepinephrine transporter polymorphisms did not influence any of these measures, which is also in favor of a role of the ADORA2A gene in anxiety disorders (Hohoff et al., 2009). Other data confirm the evidence for a susceptibility locus for panic disorder, and possibly agoraphobia, as well as for anxious personality within the ADORA2A gene or in a nearby region of chromosome 22 (Hamilton et al., 2004; Hohoff et al., 2010). This association could depend on ethnicity, because the $1976 \mathrm{C}>\mathrm{T}$ ADORA2A polymorphism is positively associated with panic disorder in a European cohort (Deckert et al., 1998) but not in a Chinese population (Lam et al., 2005). The $1976 \mathrm{C}>\mathrm{T}$ polymorphism may be in linkage disequilibrium with a functional variant that affects panic disorder, and the extent of this linkage disequilibrium may vary with ethnicity.

Moreover, adenosine receptors are colocalized and interact functionally with dopamine receptors in the brain. Thus, functional polymorphisms in the genes coding for dopamine receptors may also affect responses to caffeine. After ingestion of $150 \mathrm{mg}$ caffeine, there is a significant association between caffeine-induced anxiety and three ADORA2A SNPs: rs5751876 (1976C/T), rs2298383 (intron 1a), and rs4822492 (30-flank), as well as with one dopamine D2 receptor (DRD2) SNP: rs1110976 (intron 6). Furthermore, the combinations of ADORA2A and DRD2 polymorphisms lead to more variance in caffeine-induced anxiety than each individual SNP alone and are likely to contribute to specific responses to caffeine (Childs et al., 2008).

b. Sleep. The same variation on ADORA2A 1976T $>$ C genotype found in studies on anxiety influences the quality of sleep and divides the population in two categories, individuals sensitive (CC and $\mathrm{CT}$ ) and insensitive to caffeine (TT). The ADORA2A 1976T $>$ C polymorphism modulates the interindividual sensitivity to cortical hyperarousal accompanying acute insomnia induced by caffeine, which is known as a classic trigger of acute insomnia (Rétey et al., 2007). Caffeine consumption is positively associated with sleep latency and alpha spectral power known to occur at rest with eyes closed and to be reduced by drowsiness and sleep and negatively associated with the deep sleep stage and its characteristic delta spectral power waves. However, these associations were found in only $\mathrm{T}$ allele carriers and not in the CC genotype (Nunes et al., 2017). Of note, this ADORA2A polymorphism impacts on caffeine-induced alertness together with increasing alpha waves (Rogers et al., 2010). In addition, it is an important determinant of psychomotor vigilance in individuals rested or sleep deprived. It modulates individual responses to caffeine after sleep deprivation and could be of relevance for individuals trying to counteract impaired vigilance as a consequence of shift work or jetlag for example (Bodenman et al., 2012; Rupp et al., 2013). ADORA2AC $>\mathrm{T}$ individuals expressed greater psychomotor vigilance after sleep restriction compared with ADORA2AT $>$ T individuals and the involvement of ADORA2A polymorphisms play a more prominent role with increasing severity and/or duration of sleep restriction but the latter data were obtained in a small sample of individuals and need replication (Rupp et al., 2013).

In addition, a polymorphism on the adenosine deaminase (ADA) gene also leads to differences in sleep and sleep sensitivity to caffeine. Adenosine deaminase (ADA), which clears extracellular adenosine (Fredholm et al., 2005), contains a polymorphism on exon 1 consisting in a G-to-A transition at nucleotide 22 (ADA G22A; rs73598374) that leads to the substitution of asparagine for aspartic acid at the codon 8 of the gene (Rétey et al., 2005). In erythrocytes and lymphocytes of individuals with the GA genotype, ADA activity decreases by 20\%-30\% (Battistuzzi et al., 1981), which highlights the importance of this polymorphism as a potential marker in the regulation of adenosinedependent sleep homeostasis. The spectral characteristics of the EEG in waking and sleep, i.e., higher EEG frequencies characterizing cortical hyperarousal, vary with the $\mathrm{ADA}$ genotype. Individuals with the $22 \mathrm{G}>\mathrm{A}$ genotype wake up less frequently during the night than individuals carrying the $G>G$ genotype. The $22 \mathrm{G}>\mathrm{A}$ ADA polymorphism also modulates objective measures of sleep. Individuals with the $\mathrm{G}>\mathrm{A}$ genotype spend twofold longer in deep, stage-4 sleep, and roughly 30 minutes longer in slow-wave sleep within an 8-hour sleep period compared with the $\mathrm{G}>\mathrm{G}$ carriers. They also experience fewer awakenings and higher rapid eye movement sleep percentage (Rétey et al., 2005; Mazzotti et al., 2011). The following genotype frequencies were found in two healthy Caucasian populations: $\mathrm{G}>\mathrm{G}, \quad 88 \%-92 \%, \quad \mathrm{G}>\mathrm{A}, \quad 8 \%-12 \%, \quad \mathrm{~A}>\mathrm{A}, \quad 0.3 \%-1 \%$ (Persico et al., 2000; Mazzotti et al., 2011). Thus, the ADA G22A polymorphism plays an important role in sleep architecture and maintenance. The previous data also show that caffeine may act as a modulator of the functional effects of the ADA G22A polymorphism, especially given that the polymorphism in the gene encoding ADA is frequent, likely contributing to the high interindividual variability in sleep intensity and potential sensitivity to caffeine but needs to be further explored.

Polymorphisms have also been described at the level of the other enzymes involved in adenosine metabolism, namely CD39, CD73, adenylate kinase and $S$-adenosylhomocysteine hydrolase. Most of them have either no clear consequences on physiologic functions or pathophysiological consequences in specific diseases, like the adenylate kinase locus $1\left(A k_{1}\right)$ in Type 2 diabetes (Gloria-Bottini et al., 2011), inflammatory diseases for 
CD39 and CD73 (AIDS, autoimmune diseases, infections, atherosclerosis, ischemia-reperfusion injury, and cancer) (Antonioli et al., 2013). However, none of these polymorphisms has been described as impacting the regulation of sleep, other physiologic functions, or caffeine consumption.

In a recent GWAS testing over 2 million common SNPs for association with caffeine-induced insomnia, the authors did not find any SNP that reached the genome-wide significance threshold. In caffeine-related insomnia without adjusting for general insomnia, the most significant association was rs6575353 located in an intron of the PRIMA1 gene on chromosome 14. After inclusion of general insomnia in the analysis, the previously identified association of caffeine with a polymorphism in the ADORA2A gene at rs5751876 $(1976 \mathrm{C}>\mathrm{T})$ remained significant and the most significant SNP was rs521704 located approximately $15 \mathrm{~kb}$ upstream of the GBP4 gene on chromosome 1. Further studies are still needed in other population samples to confirm the potential role of these genes in caffeineinduced insomnia, especially since more than 600 potential genes were identified (Byrne et al., 2012).

In fact, most variants found in GWAS so far have only a limited effect on phenotype, but their association within a given pathway could be of significance. However, that type of study is missing at this point. In one study, the association analysis identified several genes involved in nucleic acid metabolism, along with many of the genes specifically involved in adenosine metabolism. This fits with the hypothesized central mode of action of caffeine and the general pathways involved in sleep (Byrne et al., 2012).

c. Neurodegenerative diseases. In a recent GWAS, in addition to the four genes potentially involved in the pharmacokinetics of caffeine (CYP1A2, AHR, ABCG2, and POR), two additional genes related to the pharmacodynamics of caffeine, namely BDNF and SLC6A4, were found to be associated with caffeine consumption and two others map to GCKR and MLXIPL genes related to metabolic traits, but their roles in coffee consumption are unknown (Cornelis et al., 2015). The potential roles of BDNF and SLC6A4 have been detailed earlier in the text.

A large consortium (PEGASUS) study combined data from five population-based case-control studies including $1325 \mathrm{PD}$ cases and 1735 controls. This study reported that PD risk was inversely associated with two ADORA2 polymorphisms, namely SNP rs5751876, a 5' variant, and rs3032740, a promoter region variant, but the potential evidence of interaction with coffee consumption was weak. In contrast, the coffee-PD association was strongest in slow caffeine metabolizers (CC genotype of rs762551 in CYP1A2) who were homozygous CC carriers compared with CA or AA carriers (Popat et al., 2011). A recent study confirmed that interactions between ADORA2A rs5760423,
CYP1A2 rs762551, and rs2472304 variants and coffee consumption affect PD risk (Chuang et al., 2016), but two studies on much smaller cohorts did not find evidence for interaction (Tan et al., 2006; Facheris et al., 2008).

A dose-dependent significant reduction of the risk of developing PD in coffee/caffeine consumers has been repeatedly shown in numerous studies (Qi and $\mathrm{Li}, 2014$; Yamada-Fowler and Söderkvist, 2015). In a GWAS concerning coffee consumption, the most significant signal was found on rs4998386 and the neighboring SNPs in the glutamate receptor gene GRIN2A. GRIN2A encodes a NMDA-glutamate-receptor subunit and regulates excitatory neurotransmission in the brain which is modulated by adenosine $\mathrm{A}_{1}$ (de Mendonça et al., 1995) and adenosine $\mathrm{A}_{2 \mathrm{~A}}$ receptors (Rebola et al., 2008). The study reported that GRIN2A was stronger than all known PD susceptibility genes that were significant in the GWAS. The signal was found in heavy but not in light coffee drinkers (Hamza et al., 2011). This relation was independently replicated in an ethnically homogenous population in southern Sweden, with significant evidence for GRIN2A-caffeine interaction with risk for PD (Yamada-Fowler et al., 2014). However, these results were not replicated in another study, which did not find any evidence for an interaction between caffeinated coffee consumption and rs4998386 for PD risk in a population originating from four independent studies (Denmark; France; Seattle, WA; and Rochester, NY). The latter study would rather suggest that the original finding may have been driven by an association of coffee consumption with rs4998386 in controls (Ahmed et al., 2014).

There are currently nine studies in the literature on PD risk as a function of GRIN2A and coffee use: four found statistically significant evidence in favor of GRIN2A being a modifier of PD-coffee association (NGRC, PAGE, Sweden, and Denmark) and three showed a consistent trend toward interaction (HIHG, PEG, and France). In addition, there is functional evidence that GRIN2A markers influence GRIN2A gene regulation (Ahmed et al., 2014). A recent study on 420 subjects reported a gene-environment interaction in PD. It showed that the GRIN2A genotype is not associated with the rate of clinical progression of $\mathrm{PD}$ in the placebo group but in high caffeine consumers taking creatine, the GRIN2A T allele is associated with more rapid progression (Simon et al., 2017). This illustrates the interaction of a genetic factor with environmental factors in the progression of PD. Clearly more studies are needed to understand this possible relationship, and it is likely that other environmental or endogenous factors influence this relation.

Moreover, at this point, a definitive association with the risk of developing PD has not been convincingly demonstrated with the polymorphisms linked to activation or detoxification of drugs and xenobiotics, such as 
CYP1A1, CYP1A2, CYP19A1, CYP1B1, CYP2C9, CYP2C19, CYP2E1, CYP2D6, NAT2, GSTM1, GSTM3, GSTO1, GSTP1, PON1, PON2, ABCB1, and ADH genes (Alonso-Navarro et al., 2014; Yamada-Fowler and Söderkvist, 2015).

d. Psychiatric disorders. A GWAS detected a significant evidence of association at rs382140 in the promoter region of the NrCAM gene involved in reward and also strongly implicated CAB39L (rs9526558) and NCALD (rs17498920) genes in coffee drinking (Amin et al., 2012). NrCAM is a neuronal cell adhesion molecule expressed in the brain and involved in several aspects of the nervous system development, including cell proliferation and differentiation, axon growth and guidance, synapse formation, and myelinization. Notably caffeine and adenosine $\mathrm{A}_{2 \mathrm{~A}}$ receptors control neuronal migration during brain development through mechanisms still to be unraveled (Silva et al., 2013). Alterations in NrCAM are associated with psychiatric disorders such as autism and altered drug reward. Addiction vulnerability has been associated with allelic variants of this gene by Ishiguro et al. (2006). Genetic variants increasing the risk of addiction may also influence coffee consumption, as twin studies reported some overlap in the heritability of coffee consumption and use of nicotine and alcohol (Swan et al., 1996). The allelic and genotypic frequencies of the rs5751876 SNP showed significant associations with methamphetamine dependence/psychosis in 171 patients compared with 229 controls. This association was particularly strong in women and/or in patients using this drug solely, leading to the hypothesis that the ADORA2A gene could be a vulnerability factor for methamphetamine dependence/psychosis in subsets of the population (Kobayashi et al., 2010).

Likewise, autism spectrum disorders (ASDs) are heterogeneous disorders associated with increased anxiety. The association with ASD symptoms depends on the rs2236624-CC and phenotypic variability and is influenced by three ADORA2 SNPs, rs3761422, rs5751876, and rs35320474. In addition, all individuals with ASD show an association of ADORA2A variants with anxiety (Freitag et al., 2010). Also, because of its link with the dopaminergic system and its role in the regulation of alertness, a potential association of ADORA2A with attention-deficit hyperactivity disorder traits was suggested. A study on 1747 twins showed a nominal association between attention-deficit hyperactivity disorder traits and three of ADORA2A SNPs, rs3761422, rs5751876, and rs35320474 (Molero et al., 2013).

ADORA1 polymorphisms might be involved in the pathophysiological mechanisms of schizophrenia in a Japanese population of 200 patients with schizophrenia compared with 210 healthy controls. Earlier studies in rats reported the antipsychotic effect of an adenosine $A_{1}$ receptor agonist and the human findings confirm that
ADORA1 polymorphism could represent a good marker of schizophrenia and detection of the patients at risk of developing adverse effects to antipsychotic therapy (Gotoh et al., 2002, 2009).

e. Caffeine consumption. The ADORA2A, but surprisingly not the CYP1A2 genotype, is associated with different amounts of caffeine intake. In individuals carrying the ADORA2A 1976TT genotype, the probability of consuming high amounts of caffeine progressively decreases with the dose. This effect is more pronounced among current smokers than among nonsmokers. Individuals with the ADORA2A 1976TT genotype also are significantly more likely to consume less caffeine $(<100 \mathrm{mg} /$ day $)$ than carriers of the $\mathrm{C}$ allele. Thus the probability of having the ADORA2A 1976TT genotype is inversely related to habitual caffeine consumption (Cornelis et al., 2007).

A very recent GWAS on an Italian population (INGI Consortium) uncovered a significant association at the level of the PDSS2 gene that codes for an enzyme responsible for the synthesis of the prenyl side chain of coenzyme Q10. The authors replicated the findings in an independent cohort from the Netherlands (ERF for Erasmus Rucphen Family) where filtered coffee is drunk rather than espresso as in the Italian population. They showed that individuals with a genetic variation of PSSD2 drank approximately one cup of coffee daily less compared with those without the variation. This gene has been shown to regulate negatively the expression of the caffeine metabolism genes and hence can be linked to coffee consumption (Pirastu et al., 2016). This is in agreement with the wealth of knowledge relating both coffee or caffeine (Dragicevic et al., 2012; Liang and Kitts, 2014) as well as their putative targets (adenosine receptors) with the rate of formation of oxygen free radicals (reviewed in Cunha, 2016), the main deleterious consequence of altered coenzyme Q10 function (reviewed in Acosta et al., 2016).

The fact that an individual would choose to abstain from coffee or drink only very small quantities may relate to subjective symptoms such as insomnia, anxiety, trembling, or other side effects of caffeine. They also reflect tolerance to some of the consequences of regular exposure to caffeine. Studies on these relationships represent critical steps in understanding the genetic variability underlying coffee/caffeine consumption. Caffeine is the most psychoactive substance consumed worldwide, and caffeine is mostly consumed in the form of coffee in the adult population. The studies detailed in the preceding paragraphs have implications for understanding individual differences in caffeine consumption but also for various other human traits and diseases such as the regulation of blood pressure, cardiac health, and vulnerability to metabolic and neurodegenerative diseases. It will most likely be informative to test whether carriers of different coffee/ caffeine consumption alleles experience the same or 
different side effects from caffeine. Analysis of individuals according to symptoms resulting from caffeine ingestion compared with controls should be very helpful for detecting caffeine-sensitive alleles. Some studies are starting to appear on these aspects, but we will need some more time and research efforts to understand better how these regulations might take place.

Finally, a study presented at the 26th ASIC Conference in Kunming (China) looked at 15 healthy volunteers that received a cup of $200 \mathrm{ml}$ of a standardized brewed coffee with a light breakfast after fasting for at least 8 hours. The CYP1A2 polymorphism was studied in this population. Three possible genotypes were found. Ninety percent of the volunteers were fast metabolizers (AA genotype), and their plasma caffeine levels varied widely, ranging from zero (not detectable) to $0.67 \mathrm{mg} / \mathrm{l}$. The two intermediate metabolizers (AC genotype) had plasma caffeine levels of 0.11 and $0.39 \mathrm{mg} / \mathrm{l}$ and one slow metabolizer (CC genotype) had a plasma caffeine level of $1.11 \mathrm{mg} / \mathrm{l}$. There is an inverse relationship between caffeine metabolism (CYP 1A2 form) and plasma caffeine levels, but as in previous studies, the authors did not detect a correlation between CYP1A2 phenotype and coffee consumption (Santos et al., 2016). Clearly more studies are needed.

\section{Conclusion}

As extensively described in this review, it appears that caffeine intake, absorption, metabolism, and physiologic and functional effects are influenced by a large variety of exogenous and endogenous factors, such as age, sex, hormonal status, diet, smoking, exposure to drugs, and genetic background. Genetics clearly play a critical role in these variations, and polymorphisms in many different genes that influence caffeine metabolism and functional consequences have been found in the last decade or so, but they still only imperfectly help understanding the whole picture. Nevertheless it appears that consumption of coffee/caffeine would rather be driven by the functional consequences of caffeine than by the rate at which the methylxanthine is metabolized. A possible research strategy to consider in the future would be to stratify differently the populations studied, possibly combining the variability in the gene alleles carried by the individuals and their consequences on various functions, based on similar or different effects or side effects from caffeine.

Given the general favorable profile of increased health and quality of life with aging of caffeine consumers, the understanding of the factor formatting the intake of caffeine might actually be a window of opportunity to foresee yet unrecognized factors with critical importance in the definition of the quality of aging and/or in the susceptibility to disease.

Conflict of Interest
Authorship Contributions

Wrote or contributed to the writing of the manuscript: Nehlig.

\section{References}

Abernethy DR and Todd EL (1985) Impairment of caffeine clearance by chronic use of low-dose oestrogen-containing oral contraceptives. Eur J Clin Pharmacol 28: $425-428$.

Acosta MJ, Vazquez Fonseca L, Desbats MA, Cerqua C, Zordan R, Trevisson E, and Salviati L (2016) Coenzyme Q biosynthesis in health and disease. Biochim Biophys Acta 1857:1079-1085.

Adehin A and Bolaji OO (2015a) Polymorphisms of CYP1A2 and CYP2A6 activity: phenotypes and the effect of age and sex in a Nigerian population. Drug Metab Pers Ther 30:203-210.

Adehin A and Bolaji OO (2015b) Distribution of xanthine oxidase activity in a Nigerian population. Eur J Clin Pharmacol 71:687-690.

Ahmed I, Lee P-C, Lill CM, Searles Nielsen S, Artaud F, Gallagher LG, Loriot MA, Mulot C, Nacfer M, Liu T, et al. (2014) Lack of replication of the GRIN2A-by-coffee interaction in Parkinson disease. PLoS Genet 10:e1004788.

Alonso-Navarro H, Jimenez-Jimenez FJ, Garcia-Martin E, and Agundez JA (2014) Genomic and pharmacogenomic biomarkers of Parkinson's disease. Curr Drug Metab 15:129-181.

Alsene K, Deckert J, Sand P, and de Wit H (2003) Association between A2a receptor gene polymorphisms and caffeine-induced anxiety. Neuropsychopharmacology $\mathbf{2 8}$ : 1694-1702.

Alvarez E, Roncero I, Chowen JA, Vázquez P, and Blázquez E (2002) Evidence that glucokinase regulatory protein is expressed and interacts with glucokinase in rat brain. J Neurochem 80:45-53.

Amchin J, Zarycranski W, Taylor KP, Albano D, and Klockowski PM (1999) Effect of venlafaxine on CYP1A2-dependent pharmacokinetics and metabolism of caffeine. $J$ Clin Pharmacol 39:252-259.

Amin N, Byrne E, Johnson J, Chenevix-Trench G, Walter S, Nolte IM, Vink JM, Rawal R, Mangino M, Teumer A, et al.; kConFab Investigators (2012) Genomewide association analysis of coffee drinking suggests association with CYP1A1/CYP1A2 and NRCAM. Mol Psychiatry 17:1116-1129.

Antonioli L, Pacher P, Vizi ES, and Haskó G (2013) CD39 and CD73 in immunity and inflammation. Trends Mol Med 19:355-367.

Arab L, Biggs ML, O'Meara ES, Longstreth WT, Crane PK, and Fitzpatrick AL (2011) Gender differences in tea, coffee, and cognitive decline in the elderly: the Cardiovascular Health Study. J Alzheimers Dis 27:553-566.

Arnaud MJ (1976) Identification, kinetic and quantitative study of $\left[2-{ }^{14} \mathrm{C}\right]$ and [1$\left.\mathrm{Me}^{14} \mathrm{C}\right]$ caffeine metabolites in rat's urine by chromatographic separations. Biochem Med 16:67-76.

Arnaud MJ (1993) Metabolism of caffeine and other components of coffee, in Caffeine, Coffee and Health (Garattini S ed) pp 43-95, Raven Press, New York.

Arnaud MJ (2011) Pharmacokinetics and metabolism of natural methylxanthines in animal and man, in Methylxanthines. Handbook of Experimental Pharmacology, vol 200, pp 33-91, Springer, Heidelberg.

Arnaud MJ and Enslen M (1992) The role of paraxanthine in mediating physiological effects of caffeine. In: 14th International Conference on Coffee Science; 1991 July 14-19; San Francisco, CA, pp 71-79, ASIC Proceedings, Paris, France.

Arold G, Donath F, Maurer A, Diefenbach K, Bauer S, Henneicke-von Zepelin HH, Friede M, and Roots I (2005) No relevant interaction with alprazolam, caffeine, tolbutamide, and digoxin by treatment with a low-hyperforin St John's wort extract. Planta Med 71:331-337.

Ascherio A, Weisskopf MG, O'Reilly EJ, McCullough ML, Calle EE, Rodriguez C, and Thun MJ (2004) Coffee consumption, gender, and Parkinson's disease mortality in the cancer prevention study II cohort: the modifying effects of estrogen. Am J Epidemiol 160:977-984.

Ascherio A, Zhang SM, Hernán MA, Kawachi I, Colditz GA, Speizer FE, and Willett WC (2001) Prospective study of caffeine consumption and risk of Parkinson's disease in men and women. Ann Neurol 50:56-63.

Azcona O, Barbanoj MJ, Torrent J, and Jané F (1995) Evaluation of the central effects of alcohol and caffeine interaction. Br J Clin Pharmacol 40:393-400.

Backman JT, Karjalainen MJ, Neuvonen M, Laitila J, and Neuvonen PJ (2006) Rofecoxib is a potent inhibitor of cytochrome P450 1A2: studies with tizanidine and caffeine in healthy subjects. Br J Clin Pharmacol 62:345-357.

Barone JJ and Roberts HR (1996) Caffeine consumption. Food Chem Toxicol 34: 119-129.

Batalha VL, Ferreira DG, Coelho JE, Valadas JS, Gomes R, Temido-Ferreira M, Shmidt T, Baqi Y, Buée L, Müller CE, et al. (2016) The caffeine-binding adenosine A2A receptor induces age-like HPA-axis dysfunction by targeting glucocorticoid receptor function. Sci Rep 6:31493.

Battistuzzi G, Iudicone P, Santolamazza P, and Petrucci R (1981) Activity of adenosine deaminase allelic forms in intact erythrocytes and in lymphocytes. Ann Hum Genet 45:15-19.

Beach CA, Mays DC, Sterman BM, and Gerber N (1985) Metabolism, distribution, seminal excretion and pharmacokinetics of caffeine in the rabbit. J Pharmacol Exp Ther 233:18-23.

Beaumont R, Cordery P, Funnell M, Mears S, James L, and Watson P (2017) Chronic ingestion of a low dose of caffeine induces tolerance to the performance benefits of caffeine. J Sports Sci 35:1920-1927.

Bell DG and McLellan TM (2002) Exercise endurance 1, 3, and $6 \mathrm{~h}$ after caffeine ingestion in caffeine users and nonusers. J Appl Physiol (1985) 93:1227-1234.

Beste C, Stock AK, Ness V, Epplen JT, and Arning L (2012) Differential effects of ADORA2A gene variations in pre-attentive visual sensory memory subprocesses. Eur Neuropsychopharmacol 22:555-561.

Birkett DJ and Miners JO (1991) Caffeine renal clearance and urine caffeine concentrations during steady state dosing. Implications for monitoring caffeine intake during sports events. Br J Clin Pharmacol 31:405-408. 
Blake MJ, Abdel-Rahman SM, Pearce RE, Leeder JS, and Kearns GL (2006) Effect of diet on the development of drug metabolism by cytochrome P-450 enzymes in healthy infants. Pediatr Res 60:717-723.

Blanchard J and Hochman D (1984) Effects of vitamin C on caffeine pharmacokinetics in young and aged guinea pigs. Drug Nutr Interact 2:243-255.

Blanchard J and Sawers SJ (1983a) The absolute bioavailability of caffeine in man. Eur J Clin Pharmacol 24:93-98.

Blanchard J and Sawers SJ (1983b) Comparative pharmacokinetics of caffeine in young and elderly men. J Pharmacokinet Biopharm 11:109-126.

Bodenmann S, Hohoff C, Freitag C, Deckert J, Rétey JV, Bachmann V, and Landolt HP (2012) Polymorphisms of ADORA2A modulate psychomotor vigilance and the effects of caffeine on neurobehavioural performance and sleep EEG after sleep deprivation. Br J Pharmacol 165:1904-1913.

Bologa M, Tang B, Klein J, Tesoro A, and Koren G (1991) Pregnancy-induced changes in drug metabolism in epileptic women. $J$ Pharmacol Exp Ther 257:735-740.

Bonati M, Latini R, Galletti F, Young JF, Tognoni G, and Garattini S (1982) Caffeine disposition after oral doses. Clin Pharmacol Ther 32:98-106.

Bonati M, Latini R, Tognoni G, Young JF, and Garattini S (1984-1985) Interspecies comparison of in vivo caffeine pharmacokinetics in man, monkey, rabbit, rat, and mouse. Drug Metab Rev 15:1355-1383.

Bory C, Baltassat P, Porthault M, Bethenod M, Frederich A, and Aranda JV (1979) Metabolism of theophylline to caffeine in premature newborn infants. J Pediatr 94 988-993

Brachtel D and Richter E (1988) Effect of altered gastric emptying on caffeine absorption. Z Gastroenterol 26:245-251.

Braff DL, Geyer MA, and Swerdlow NR (2001) Human studies of prepulse inhibition of startle: normal subjects, patient groups, and pharmacological studies. Psychopharmacology (Berl) 156:234-258.

Brown CR, Jacob P 3rd, Wilson M, and Benowitz NL (1988) Changes in rate and pattern of caffeine metabolism after cigarette abstinence. Clin Pharmacol Ther $\mathbf{4 3}$ 488-491.

Bruguerolle B, Toumi M, Faraj F, Vervloet D, and Razzouk H (1990) Influence of the menstrual cycle on theophylline pharmacokinetics in asthmatics. Eur $\mathrm{J}$ Clin Pharmacol 39:59-61.

Butler MA, Lang NP, Young JF, Caporaso NE, Vineis P, Hayes RB, Teitel CH, Massengill JP, Lawsen MF, and Kadlubar FF (1992) Determination of CYP1A2 and NAT2 phenotypes in human populations by analysis of caffeine urinary metabolites. Pharmacogenetics 2:116-127.

Byrne EM, Johnson J, McRae AF, Nyholt DR, Medland SE, Gehrman PR, Heath AC, Madden PA, Montgomery GW, Chenevix-Trench G, et al. (2012) A genome-wide association study of caffeine-related sleep disturbance: confirmation of a role for a common variant in the adenosine receptor. Sleep (Basel) 35:967-975.

Caetano L, Pinheiro H, Patrício P, Mateus-Pinheiro A, Alves ND, Coimbra B, Baptista FI, Henriques SN, Cunha C, Santos AR, et al. (2017) Adenosine A2A receptor regulation of microglia morphological remodeling-gender bias in physiology and in a model of chronic anxiety. Mol Psychiatry 22:1035-1043.

Caldeira D, Martins C, Alves LB, Pereira H, Ferreira JJ, and Costa J (2013) Caffeine does not increase the risk of atrial fibrillation: a systematic review and metaanalysis of observational studies. Heart 99:1383-1389.

Callahan MM, Robertson RS, Arnaud MJ, Branfman AR, McComish MF, and Yesair DW (1982) Human metabolism of $\left[1-\right.$ methy $\left.^{-14} \mathrm{C}\right]-$ and $\left[2^{-14} \mathrm{C}\right]$ caffeine after oral administration. Drug Metab Dispos 10:417-423.

Caraco Y, Zylber-Katz E, Berry EM, and Levy M (1995) Caffeine pharmacokinetics in obesity and following significant weight reduction. Int J Obes Relat Metab Disord 19:234-239.

Carrillo JA and Benitez J (1996) CYP1A2 activity, gender and smoking, as variables influencing the toxicity of caffeine. Br J Clin Pharmacol 41:605-608.

Carrillo JA and Benitez J (2000) Clinically significant pharmacokinetic interactions between dietary caffeine and medications. Clin Pharmacokinet 39:127-153.

Chen Y, Liu WH, Chen BL, Fan L, Han Y, Wang G, Hu DL, Tan ZR, Zhou G, Cao S, et al. (2010) Plant polyphenol curcumin significantly affects CYP1A2 and CYP2A6 activity in healthy, male Chinese volunteers. Ann Pharmacother 44:1038-1045.

Chen Y, Tu JH, He YJ, Zhang W, Wang G, Tan ZR, Zhou G, Fan L, and Zhou HH (2009a) Effect of sodium tanshinone II A sulfonate on the activity of CYP1A2 in healthy volunteers. Xenobiotica 39:508-513.

Chen Y, Xiao P, Ou-Yang DS, Fan L, Guo D, Wang YN, Han Y, Tu JH, Zhou G, Huang $\mathrm{YF}$, et al. (2009b) Simultaneous action of the flavonoid quercetin on cytochrome $\mathrm{P} 450$ (CYP) 1A2, CYP2A6, N-acetyltransferase and xanthine oxidase activity in healthy volunteers. Clin Exp Pharmacol Physiol 36:828-833.

Cheng WS, Murphy TL, Smith MT, Cooksley WG, Halliday JW, and Powell LW (1990) Dose-dependent pharmacokinetics of caffeine in humans: relevance as a test of quantitative liver function. Clin Pharmacol Ther 47:516-524.

Chien CF, Wu YT, Lee WC, Lin LC, and Tsai TH (2010) Herb-drug interaction of Andrographis paniculata extract and andrographolide on the pharmacokinetics of theophylline in rats. Chem Biol Interact 184:458-465.

Childs E, Hohoff C, Deckert J, Xu K, Badner J, and de Wit H (2008) Association between ADORA2A and DRD2 polymorphisms and caffeine-induced anxiety. Neuropsychopharmacology 33:2791-2800.

Chrościńska-Krawczyk M, Jargiełło-Baszak M, Andres-Mach M, Łuszczki JJ, and Czuczwar SJ (2016) Influence of caffeine on the protective activity of gabapentin and topiramate in a mouse model of generalized tonic-clonic seizures. Pharmacol Rep 68:680-685.

Chrościńska-Krawczyk M, Ratnaraj N, Patsalos PN, and Czuczwar SJ (2009) Effect of caffeine on the anticonvulsant effects of oxcarbazepine, lamotrigine and tiagabine in a mouse model of generalized tonic-clonic seizures. Pharmacol Rep 61:819-826.

Chuang YH, Lill CM, Lee PC, Hansen J, Lassen CF, Bertram L, Greene N, Sinsheimer JS, and Ritz B (2016) Gene-environment interaction in Parkinson's disease: coffee, ADORA2A, and CYP1A2. Neuroepidemiology 47:192-200.

Chvasta TE and Cooke AR (1971) Emptying and absorption of caffeine from the human stomach. Gastroenterology 61:838-843.
Cornelis MC (2015) Toward systems epidemiology of coffee and health. Curr Opin Lipidol 26:20-29.

Cornelis MC, Byrne EM, Esko T, Nalls MA, Ganna A, Paynter N, Monda KL, Amin N, Fischer K, Renstrom F, et al.; Coffee and Caffeine Genetics Consortium; ; International Parkinson's Disease Genomics Consortium (IPDGC); ; North American Brain Expression Consortium (NABEC); ; UK Brain Expression Consortium (UKBEC) (2015) Genome-wide meta-analysis identifies six novel loci associated with habitual coffee consumption. Mol Psychiatry 20:647-656.

Cornelis MC, El-Sohemy A, and Campos H (2007) Genetic polymorphism of the adenosine A2A receptor is associated with habitual caffeine consumption. Am J Clin Nutr 86:240-244.

Cornelis MC, El-Sohemy A, Kabagambe EK, and Campos H (2006) Coffee, CYP1A2 genotype, and risk of myocardial infarction. JAMA 295:1135-1141.

Cornelis MC, Kacprowski T, Menni C, Gustafsson S, Pivin E, Adamski J, Artati A Eap CB, Ehret G, Friedrich N, et al.; Swiss Kidney Project on Genes in Hypertension (SKIPOGH) team (2016) Genome-wide association study of caffeine metabolites provides new insights to caffeine metabolism and dietary caffeineconsumption behavior. Hum Mol Genet 25:5472-5482

Cornelis MC, Monda KL, Yu K, Paynter N, Azzato EM, Bennett SN, Berndt SI, Boerwinkle E, Chanock S, Chatterjee N, et al. (2011) Genome-wide meta-analysis identifies regions on 7p21 (AHR) and 15q24 (CYP1A2) as determinants of habitual caffeine consumption. PLoS Genet 7:e1002033.

Culm-Merdek KE, von Moltke LL, Harmatz JS, and Greenblatt DJ (2005) Fluvoxamine impairs single-dose caffeine clearance without altering caffeine pharmacodynamics. Br J Clin Pharmacol 60:486-493.

Cunha RA (2016) How does adenosine control neuronal dysfunction and neurodegeneration? J Neurochem 139:1019-1055.

Curtis BR (2014a) Drug-induced immune thrombocytopenia: incidence, clinical features, laboratory testing, and pathogenic mechanisms. Immunohematology 30:55-65.

Curtis BR (2014b) Drug-induced immune neutropenia/agranulocytosis. Immunohematology 30:95-101.

Cysneiros RM, Farkas D, Harmatz JS, von Moltke LL, and Greenblatt DJ (2007) Pharmacokinetic and pharmacodynamic interactions between zolpidem and caffeine. Clin Pharmacol Ther 82:54-62.

Czuczwar SJ, Gasior M, Janusz W, Szczepanik B, Włodarczyk D, and Kleinrok Z (1990) Influence of different methylxanthines on the anticonvulsant action of common antiepileptic drugs in mice. Epilepsia 31:318-323.

Darwish M, Kirby M, Robertson P Jr, and Hellriegel ET (2008) Interaction profile of armodafinil with medications metabolized by cytochrome P450 enzymes 1A2, 3A4 and 2C19 in healthy subjects. Clin Pharmacokinet 47:61-74.

Debry G ed (1994) Coffee and Health, John Libbey, Montrouge, France.

Deckert J, Nothen MM, Franke P, Delmo C, Fritze J, Knapp M, Maier W, Beckmann $\mathrm{H}$, and Propping $\mathrm{P}$ (1998) Systematic mutation screening and association study of the $\mathrm{A} 1$ and $\mathrm{A} 2 \mathrm{~A}$ adenosine receptor genes in panic disorder suggest a contribution of the A2A gene to the development of disease. Mol Psychiatry 3: 81-5.

Delbeke FT and Debackere M (1988) The influence of diuretics on the excretion and metabolism of doping agents. Part IV--Caffeine. Biopharm Drug Dispos 9:137-145.

de Mendonça A, Sebastião AM, and Ribeiro JA (1995) Inhibition of NMDA receptormediated currents in isolated rat hippocampal neurones by adenosine A1 receptor activation. Neuroreport 6:1097-1100

Denaro CP, Brown CR, Wilson M, Jacob P 3rd, and Benowitz NL (1990) Dose-dependency of caffeine metabolism with repeated dosing. Clin Pharmacol Ther 48 : $277-285$.

Denden S, Bouden B, Haj Khelil A, Ben Chibani J, and Hamdaoui MH (2016) Gender and ethnicity modify the association between the CYP1A2 rs762551 polymorphism and habitual coffee intake: evidence from a meta-analysis. Genet Mol Res 15.

Derry CJ, Derry S, and Moore RA (2014) Caffeine as an analgesic adjuvant for acute pain in adults. Cochrane Database Syst Rev 12:CD009281.

Desmond PV, Patwardhan RV, Johnson RF, and Schenker S (1980) Impaired elimination of caffeine in cirrhosis. Dig Dis Sci 25:193-197.

Dik VK, Bueno-de-Mesquita HB, Van Oijen MG, Siersema PD, Uiterwaal CS, Van Gils CH, Van Duijnhoven FJ, Cauchi S, Yengo L, Froguel P, et al. (2014) Coffee and tea consumption, genotype-based CYP1A2 and NAT2 activity and colorectal cancer risk-results from the EPIC cohort study. Int J Cancer 135:401-412.

Dinger J, Woods C, Brandt SD, Meyer MR, and Maurer HH (2016) Cytochrome P450 inhibition potential of new psychoactive substances of the tryptamine class. Toxicol Lett 241:82-94.

Djordjevic N, Carrillo JA, Roh HK, Karlsson S, Ueda N, Bertilsson L, and Aklillu E (2012) Comparison of $\mathrm{N}$-acetyltransferase-2 enzyme genotype-phenotype and xanthine oxidase enzyme activity between Swedes and Koreans. J Clin Pharmacol 52:1527-1534

Djordjevic N, Carrillo JA, Ueda N, Gervasini G, Fukasawa T, Suda A, Jankovic S, and Aklillu E (2011) N-Acetyltransferase-2 (NAT2) gene polymorphisms and enzyme activity in Serbs: unprecedented high prevalence of rapid acetylators in a White population. J Clin Pharmacol 51:994-1003.

Djordjevic N, Carrillo JA, van den Broek MP, Kishikawa J, Roh HK, Bertilsson L, and Aklillu E (2013) Comparisons of CYP2A6 genotype and enzyme activity between Swedes and Koreans. Drug Metab Pharmacokinet 28:93-97.

Djordjevic N, Ghotbi R, Bertilsson L, Jankovic S, and Aklillu E (2008) Induction of CYP1A2 by heavy coffee consumption in Serbs and Swedes. Eur J Clin Pharmacol 64:381-385.

Doepker C, Lieberman HR, Smith AP, Peck JD, El-Sohemy A, and Welsh BT (2016) Caffeine: friend or foe? Annu Rev Food Sci Technol 7:117-137.

Domschke K and Deckert J (2012) Genetics of anxiety disorders - status quo and quo vadis. Curr Pharm Des 18:5691-5698.

Donovan JL and DeVane CL (2001) A primer on caffeine pharmacology and its drug interactions in clinical psychopharmacology. Psychopharmacol Bull 35:30-48.

Dragicevic N, Delic V, Cao C, Copes N, Lin X, Mamcarz M, Wang L, Arendash GW, and Bradshaw PC (2012) Caffeine increases mitochondrial function and blocks 
melatonin signaling to mitochondria in Alzheimer's mice and cells. Neuropharmacology 63:1368-1379.

El Yacoubi M, Ledent C, Parmentier M, Costentin J, and Vaugeois JM (2005) Reduced appetite for caffeine in adenosine $\mathrm{A}(2 \mathrm{~A})$ receptor knockout mice. Eur $J$ Pharmacol 519:290-291.

European Food Safety Authority (EFSA) (2015) Scientific opinion on the safety of caffeine: EFSA Panel on Dietetic Products, Nutrition and Allergies (NDA). EFSA J 13:4102.

Evans SM and Griffiths RR (1992) Caffeine tolerance and choice in humans. Psychopharmacology (Berl) 108:51-59.

Faber MS and Fuhr U (2004) Time response of cytochrome P450 1A2 activity on cessation of heavy smoking. Clin Pharmacol Ther 76:178-184.

Facheris MF, Schneider NK, Lesnick TG, de Andrade M, Cunningham JM, Rocca WA, and Maraganore DM (2008) Coffee, caffeine-related genes, and Parkinson's disease: a case-control study. Mov Disord 23:2033-2040.

Ferré S (2008) An update on the mechanisms of the psychostimulant effects of caffeine. J Neurochem 105:1067-1079.

Fillmore MT, Roach EL, and Rice JT (2002) Does caffeine counteract alcohol-induced impairment? The ironic effects of expectancy. J Stud Alcohol 63:745-754.

Frary CD, Johnson RK, and Wang MQ (2005) Food sources and intakes of caffeine in the diets of persons in the United States. J Am Diet Assoc 105:110-113.

Fredholm BB, Bättig K, Holmén J, Nehlig A, and Zvartau EE (1999) Actions of caffeine in the brain with special reference to factors that contribute to its widespread use. Pharmacol Rev 51:83-133.

Fredholm BB, Chen JF, Cunha RA, Svenningsson P, and Vaugeois JM (2005) Adenosine and brain function. Int Rev Neurobiol 63:191-270.

Freitag CM, Agelopoulos K, Huy E, Rothermundt M, Krakowitzky P, Meyer J, Deckert J, von Gontard A, and Hohoff C (2010) Adenosine A(2A) receptor gene (ADORA2A) variants may increase autistic symptoms and anxiety in autism spectrum disorder. Eur Child Adolesc Psychiatry 19:67-74.

Fritz BM, Companion M, and Boehm SL (2014) "Wired," yet intoxicated: modeling binge caffeine and alcohol co-consumption in the mouse. Alcohol Clin Exp Res 38: $2269-2278$.

Fuhr U, Anders EM, Mahr G, Sörgel F, and Staib AH (1992) Inhibitory potency of quinolone antibacterial agents against cytochrome P450IA2 activity in vivo and in vitro. Antimicrob Agents Chemother 36:942-948.

Fuhr U, Klittich K, and Staib AH (1993) Inhibitory effect of grapefruit juice and its bitter principal, naringenin, on CYP1A2 dependent metabolism of caffeine in man. Br J Clin Pharmacol 35:431-436.

Fuhr U, Maier A, Keller A, Steinijans VW, Sauter R, and Staib AH (1995) Lacking effect of grapefruit juice on theophylline pharmacokinetics. Int J Clin Pharmacol Ther 33:311-314.

Gajewska A, Blumenthal TD, Winter B, Herrmann MJ, Conzelmann A, Mühlberger A, Warrings B, Jacob C, Arolt V, Reif A, et al. (2013) Effects of ADORA2A gene variation and caffeine on prepulse inhibition: a multi-level risk model of anxiety. Prog Neuropsychopharmacol Biol Psychiatry 40:115-121.

Gasior M, Borowicz K, Kleinrok Z, and Czuczwar SJ (1996) Chronic caffeine and the anticonvulsant potency of antiepileptic drugs against maximal electroshock. Pharmacol Biochem Behav 54:639-644.

Gasior M, Swiader M, Przybyłko M, Borowicz K, Turski WA, Kleinrok Z, and Czuczwar SJ (1998) Felbamate demonstrates low propensity for interaction with methylxanthines and $\mathrm{Ca} 2+$ channel modulators against experimental seizures in mice. Eur J Pharmacol 352:207-214.

Geiger MJ, Domschke K, Homola GA, Schulz SM, Nowak J, Akhrif A, Pauli P, Deckert J, and Neufang S (2016) ADORA2A genotype modulates interoceptive and exteroceptive processing in a fronto-insular network. Eur Neuropsychopharmacol 26:1274-1285.

George J, Murphy T, Roberts R, Cooksley WG, Halliday JW, and Powell LW (1986) Influence of alcohol and caffeine consumption on caffeine elimination. Clin Exp Pharmacol Physiol 13:731-736.

Gloria-Bottini F, Antonacci E, Cozzoli E, De Acetis C, and Bottini E (2011) Adenylate kinase locus 1 genetic polymorphism and type 2 diabetes. Health 3:77-81.

Goldstein ER, Ziegenfuss T, Kalman D, Kreider R, Campbell B, Wilborn C, Taylor L, Willoughby D, Stout J, Graves BS, et al. (2010) International society of sports nutrition position stand: caffeine and performance. J Int Soc Sports Nutr 7:5.

Gotoh L, Kawanami N, Nakahara T, Hondo H, Motomura K, Ohta E, Kanchiku I, Kuroki T, Hirano M, and Uchimura H (2002) Effects of the adenosine A(1) receptor agonist $\mathrm{N}(6)$-cyclopentyladenosine on phencyclidine-induced behavior and expression of the immediate-early genes in the discrete brain regions of rats. Brain Res Mol Brain Res 100:1-12.

Gotoh L, Mitsuyasu H, Kobayashi Y, Oribe N, Takata A, Ninomiya H, Stanton VP Jr, Springett GM, Kawasaki H, and Kanba S (2009) Association analysis of adenosine A1 receptor gene (ADORA1) polymorphisms with schizophrenia in a Japanese population. Psychiatr Genet 19:328-335.

Granfors MT, Backman JT, Laitila J, and Neuvonen PJ (2005) Oral contraceptives containing ethinyl estradiol and gestodene markedly increase plasma concentrations and effects of tizanidine by inhibiting cytochrome P450 1A2. Clin Pharmacol Ther 78:400-411.

Granfors MT, Backman JT, Neuvonen M, and Neuvonen PJ (2004) Ciprofloxacin greatly increases concentrations and hypotensive effect of tizanidine by inhibiting its cytochrome P450 1A2-mediated presystemic metabolism. Clin Pharmacol Ther 76:598-606.

Grosso G, Godos J, Galvano F, and Giovannucci EL (2017) Coffee, caffeine, and health outcomes: an umbrella review. Annu Rev Nutr 37:131-156.

Grosso LM and Bracken MB (2005) Caffeine metabolism, genetics, and perinatal outcomes: a review of exposure assessment considerations during pregnancy. Ann Epidemiol 15:460-466.

Grosso LM, Triche E, Benowitz NL, and Bracken MB (2008) Prenatal caffeine assessment: fetal and maternal biomarkers or self-reported intake? Ann Epidemiol 18:172-178.
Gu L, Gonzalez FJ, Kalow W, and Tang BK (1992) Biotransformation of caffeine, paraxanthine, theobromine and theophylline by cDNA-expressed human CYP1A2 and CYP2E1. Pharmacogenetics 2:73-77.

Guo WC, Lin GF, Zha YL, Lou KJ, Ma QW, and Shen JH (2004) N-Acetyltransferase 2 gene polymorphism in a group of senile dementia patients in Shanghai suburb. Acta Pharmacol Sin 25:1112-1117.

Gurley BJ, Gardner SF, Hubbard MA, Williams DK, Gentry WB, Carrier J, Khan IA Edwards DJ, and Shah A (2004) In vivo assessment of botanical supplementation on human cytochrome P450 phenotypes: Citrus aurantium, Echinacea purpurea, milk thistle, and saw palmetto. Clin Pharmacol Ther 76:428-440.

Gurley BJ, Gardner SF, Hubbard MA, Williams DK, Gentry WB, Cui Y, and Ang CY (2005a) Clinical assessment of effects of botanical supplementation on cytochrome P450 phenotypes in the elderly: St John's wort, garlic oil, Panax ginseng and Ginkgo biloba. Drugs Aging 22:525-539.

Gurley BJ, Gardner SF, Hubbard MA, Williams DK, Gentry WB, Khan IA, and Shah A (2005b) In vivo effects of goldenseal, kava kava, black cohosh, and valerian on human cytochrome P450 1A2, 2D6, 2E1, and 3A4/5 phenotypes. Clin Pharmacol Ther 77:415-426.

Ha HR, Chen J, Krahenbuhl S, and Follath F (1996) Biotransformation of caffeine by cDNA-expressed human cytochromes P-450. Eur J Clin Pharmacol 49:309-315.

Hamilton SP, Slager SL, De Leon AB, Heiman GA, Klein DF, Hodge SE, Weissman MM, Fyer AJ, and Knowles JA (2004) Evidence for genetic linkage between a polymorphism in the adenosine $2 \mathrm{~A}$ receptor and panic disorder. Neuropsychopharmacology 29:558-565.

Hamon-Vilcot B, Simon T, Becquemont L, Poirier JM, Piette F, and Jaillon P (2004) Effects of malnutrition on cytochrome P450 1A2 activity in elderly patients. Therapie 59:247-251

Hamza TH, Chen H, Hill-Burns EM, Rhodes SL, Montimurro J, Kay DM, Tenesa A, Kusel VI, Sheehan P, Eaaswarkhanth M, et al. (2011) Genome-wide geneenvironment study identifies glutamate receptor gene GRIN2A as a Parkinson's disease modifier gene via interaction with coffee. PLoS Genet 7:e1002237.

Hashiguchi M, Fujimura A, Ohashi K, and Ebihara A (1992) Diurnal effect on caffeine clearance. J Clin Pharmacol 32:184-187.

Haskó G and Cronstein B (2011) Methylxanthines and inflammatory cells. Handb Exp Pharmacol (200):457-468.

Heckman MA, Weil J, and Gonzalez de Mejia E (2010) Caffeine (1, 3, 7-trimethylxanthine) in foods: a comprehensive review on consumption, functionality, safety, and regulatory matters. J Food Sci 75:R77-R87.

Heinz AJ, de Wit H, Lilje TC, and Kassel JD (2013) The combined effects of alcohol, caffeine, and expectancies on subjective experience, impulsivity, and risk-taking. Exp Clin Psychopharmacol 21:222-234.

Hermann R and von Richter O (2012) Clinical evidence of herbal drugs as perpetrators of pharmacokinetic drug interactions. Planta Med 78:1458-1477.

Hohoff C, Domschke K, Schwarte K, Spellmeyer G, Vögele C, Hetzel G, Deckert J, and Gerlach AL (2009) Sympathetic activity relates to adenosine A(2A) receptor gene variation in blood-injury phobia. J Neural Transm (Vienna) 116:659-662.

Hohoff C, Mullings EL, Heatherley SV, Freitag CM, Neumann LC, Domschke K, Krakowitzky P, Rothermundt M, Keck ME, Erhardt A, et al. (2010) Adenosine A (2A) receptor gene: evidence for association of risk variants with panic disorder and anxious personality. J Psychiatr Res 44:930-937.

Howland J, Rohsenow DJ, Arnedt JT, Bliss CA, Hunt SK, Calise TV, Heeren T, Winter M, Littlefield C, and Gottlieb DJ (2011) The acute effects of caffeinated versus non-caffeinated alcoholic beverage on driving performance and attention/reaction time. Addiction 106:335-341.

Huang ZL, Qu WM, Eguchi N, Chen JF, Schwarzschild MA, Fredholm BB, Urade Y, and Hayaishi $\mathrm{O}$ (2005) Adenosine A2A, but not A1, receptors mediate the arousal effect of caffeine. Nat Neurosci 8:858-859.

Ishiguro H, Liu QR, Gong JP, Hall FS, Ujike H, Morales M, Sakurai T, Grumet M, and Uhl GR (2006) NrCAM in addiction vulnerability: positional cloning, drugregulation, haplotype-specific expression, and altered drug reward in knockout mice. Neuropsychopharmacology 31:572-584.

Ishikawa T, Takahashi S, Morita K, Okinaga H, and Teramoto T (2014) Induction of AhR-mediated gene transcription by coffee. PLoS One 9:e102152.

Ito K, Lim S, Caramori G, Cosio B, Chung KF, Adcock IM, and Barnes PJ (2002) A molecular mechanism of action of theophylline: induction of histone deacetylase activity to decrease inflammatory gene expression. Proc Natl Acad Sci USA 99:8921-8926.

Jan WC, Lin LC, Chieh-Fu-Chen, and Tsai TH (2005) Herb-drug interaction of Evodia rutaecarpa extract on the pharmacokinetics of theophylline in rats. $J$ Ethnopharmacol 102:440-445.

Jankiewicz K, Chrościńska-Krawczyk M, Błaszczyk B, and Czuczwar SJ (2007) [Caffeine and antiepileptic drugs: experimental and clinical data]. Przegl Lek 64: 965-967.

Jaquet M, Rochat I, Moulin J, Cavin C, and Bibiloni R (2009) Impact of coffee consumption on the gut microbiota: a human volunteer study. Int $J$ Food Microbiol 130:117-121.

Jarboe CH, Hurst HE, Rodgers GC Jr, and Metaxas JM (1986) Toxicokinetics of caffeine elimination in an infant. $J$ Toxicol Clin Toxicol 24:415-428.

Jeppesen U, Loft S, Poulsen HE, and Brśen K (1996) A fluvoxamine-caffeine interaction study. Pharmacogenetics 6:213-222.

Jodynis-Liebert J, Flieger J, Matuszewska A, and Juszczyk J (2004) Serum metabolite/caffeine ratios as a test for liver function. J Clin Pharmacol 44:338-347.

Joeres R, Klinker H, Heusler H, Epping J, and Richter E (1987) Influence of mexiletine on caffeine elimination. Pharmacol Ther 33:163-169.

Johnson-Kozlow M, Kritz-Silverstein D, Barrett-Connor E, and Morton D (2002) Coffee consumption and cognitive function among older adults. Am J Epidemiol 156:842-850.

Josse AR, Da Costa LA, Campos H, and El-Sohemy A (2012) Associations between polymorphisms in the AHR and CYP1A1-CYP1A2 gene regions and habitual caffeine consumption. Am J Clin Nutr 96:665-671. 
Kalow W (1986) Ethnic differences in reactions to drugs and xenobiotics. Caffeine and other drugs. Prog Clin Biol Res 214:331-341.

Kalow W and Tang BK (1991a) Use of caffeine metabolite ratios to explore CYP1A2 and xanthine oxidase activities. Clin Pharmacol Ther 50:508-519.

Kalow W and Tang BK (1991b) Caffeine as a metabolic probe: exploration of the enzyme-inducing effect of cigarette smoking. Clin Pharmacol Ther 49:44-48.

Kamimori GH, Somani SM, Knowlton RG, and Perkins RM (1987) The effects of obesity and exercise on the pharmacokinetics of caffeine in lean and obese volunteers. Eur J Clin Pharmacol 31:595-600.

Kawachi I, Willett WC, Colditz GA, Stampfer MJ, and Speizer FE (1996) A prospective study of coffee drinking and suicide in women. Arch Intern Med 156: $521-525$.

Khanna NN and Somani SM (1984) Maternal coffee drinking and unusually high concentrations of caffeine in the newborn. J Toxicol Clin Toxicol 22:473-483.

Kinzig-Schippers M, Fuhr U, Zaigler M, Dammeyer J, Rüsing G, Labedzki A, Bulitta J, and Sörgel F (1999) Interaction of pefloxacin and enoxacin with the human cytochrome P450 enzyme CYP1A2. Clin Pharmacol Ther 65:262-274.

Kobayashi H, Ujike H, Iwata N, Inada T, Yamada M, Sekine Y, Uchimura N, Iyo M, Ozaki N, Itokawa M, et al. (2010) The adenosine A2A receptor is associated with methamphetamine dependence/psychosis in the Japanese population. Behav Brain Funct 6:50

Lachance MP, Marlowe C, and Waddell WJ (1983) Autoradiographic disposition of [1methyl- $\left.{ }^{14} \mathrm{C}\right]-$ and $\left[2-{ }^{14} \mathrm{C}\right]$ caffeine in mice. Toxicol Appl Pharmacol 71:237-241.

Laitala VS, Kaprio J, and Silventoinen K (2008) Genetics of coffee consumption and its stability. Addiction 103:2054-2061.

Lam P, Hong CJ, and Tsai SJ (2005) Association study of A2a adenosine receptor genetic polymorphism in panic disorder. Neurosci Lett 378:98-101.

Lampe JW, King IB, Li S, Grate MT, Barale KV, Chen C, Feng Z, and Potter JD (2000) Brassica vegetables increase and apiaceous vegetables decrease cytochrome P450 1A2 activity in humans: changes in caffeine metabolite ratios in response to controlled vegetable diets. Carcinogenesis 21:1157-1162.

Landi MT, Sinha R, Lang NP, and Kadlubar FF (1999) Human cytochrome P4501A2. IARC Sci Publ 148:173-195.

Lane JD, Steege JF, Rupp SL, and Kuhn CM (1992) Menstrual cycle effects on caffeine elimination in the human female. Eur J Clin Pharmacol 43:543-546.

Ledent C, Vaugeois JM, Schiffmann SN, Pedrazzini T, El Yacoubi M, Vanderhaeghen JJ, Costentin J, Heath JK, Vassart G, and Parmentier M (1997) Aggressiveness, hypoalgesia and high blood pressure in mice lacking the adenosine A2a receptor. Nature 388:674-678.

Lee CA, Thummel KE, Kalhorn TF, Nelson SD, and Slattery JT (1991) Activation of acetaminophen-reactive metabolite formation by methylxanthines and known cytochrome P-450 activators. Drug Metab Dispos 19:966-971.

Lee MA, Flegel P, Greden JF, and Cameron OG (1988) Anxiogenic effects of caffeine on panic and depressed patients. Am J Psychiatry 145:632-635.

Lelo A, Birkett DJ, Robson RA, and Miners JO (1986a) Comparative pharmacokinetics of caffeine and its primary demethylated metabolites paraxanthine, theobromine and theophylline in man. Br J Clin Pharmacol 22:177-182.

Lelo A, Miners JO, Robson RA, and Birkett DJ (1986b) Quantitative assessment of caffeine partial clearances in man. Br J Clin Pharmacol 22:183-186.

Le Marchand L, Franke AA, Custer L, Wilkens LR, and Cooney RV (1997) Lifestyle and nutritional correlates of cytochrome CYP1A2 activity: inverse associations with plasma lutein and alpha-tocopherol. Pharmacogenetics 7:11-19.

Le Marchand L, Sivaraman L, Franke AA, Custer LJ, Wilkens LR, Lau AF, and Cooney RV (1996) Predictors of N-acetyltransferase activity: should caffeine phenotyping and NAT2 genotyping be used interchangeably in epidemiological studies? Cancer Epidemiol Biomarkers Prev 5:449-455.

Liang N and Kitts DD (2014) Antioxidant property of coffee components: assessment of methods that define mechanisms of action. Molecules 19:19180-19208.

Liguori A and Robinson JH (2001) Caffeine antagonism of alcohol-induced driving impairment. Drug Alcohol Depend 63:123-129.

Loft S, Døssing M, and Poulsen HE (1988) Influence of age and consumption of tobacco, alcohol and caffeine on antipyrine clearance. Hum Toxicol 7:277-280.

Lovallo WR, Whitsett TL, al'Absi M, Sung BH, Vincent AS, and Wilson MF (2005) Caffeine stimulation of cortisol secretion across the waking hours in relation to caffeine intake levels. Psychosom Med 67:734-739.

Lucas M, Mirzaei F, Pan A, Okereke OI, Willett WC, O’Reilly ÉJ, Koenen K, and Ascherio A (2011) Coffee, caffeine, and risk of depression among women. Arch Intern Med 171:1571-1578.

Luciano M, Kirk KM, Heath AC, and Martin NG (2005) The genetics of tea and coffee drinking and preference for source of caffeine in a large community sample of Australian twins. Addiction 100:1510-1517.

Luszczki JJ, Zuchora M, Sawicka KM, Kozińska J, and Czuczwar SJ (2006) Acute exposure to caffeine decreases the anticonvulsant action of ethosuximide, but not that of clonazepam, phenobarbital and valproate against pentetrazole-induced seizures in mice. Pharmacol Rep 58:652-659.

MacKenzie T, Comi R, Sluss P, Keisari R, Manwar S, Kim J, Larson R, and Baron JA (2007) Metabolic and hormonal effects of caffeine: randomized, double-blind, placebo-controlled crossover trial. Metabolism 56:1694-1698.

Marks V and Kelly JF (1973) Absorption of caffeine from tea, coffee, and coca cola. Lancet 1:827.

Matzke GR, Frye RF, Early JJ, Straka RJ, and Carson SW (2000) Evaluation of the influence of diabetes mellitus on antipyrine metabolism and CYP1A2 and CYP2D6 activity. Pharmacotherapy 20:182-190.

Mazzotti DR, Guindalini C, Pellegrino R, Barrueco KF, Santos-Silva R, Bittencourt LR, and Tufik S (2011) Effects of the adenosine deaminase polymorphism and caffeine intake on sleep parameters in a large population sample. Sleep (Basel) 34 399-402

McLean C and Graham TE (2002) Effects of exercise and thermal stress on caffeinepharmacokinetics in men and eumenorrheic women. J Appl Physiol 93: $1471-1478$
Molero Y, Gumpert C, Serlachius E, Lichtenstein P, Walum H, Johansson D, Anckarsäter H, Westberg L, Eriksson E, and Halldner L (2013) A study of the possible association between adenosine A2A receptor gene polymorphisms and attention-deficit hyperactivity disorder traits. Genes Brain Behav 12:305-310.

Montesinos MC, Yap JS, Desai A, Posadas I, McCrary CT, and Cronstein BN (2000) Reversal of the antiinflammatory effects of methotrexate by the nonselective adenosine receptor antagonists theophylline and caffeine: evidence that the antiinflammatory effects of methotrexate are mediated via multiple adenosine receptors in rat adjuvant arthritis. Arthritis Rheum 43:656-663.

Moraidis I and Bingmann D (1994) Epileptogenic actions of xanthines in relation to their affinities for adenosine A1 receptors in CA3 neurons of hippocampal slices (guinea pig). Brain Res 640:140-145.

Morisot C, Simoens C, Trublin F, Lhermitte M, Gremillet C, Robert MH, and Lequien $\mathrm{P}$ (1990) [Efficacy of percutaneous caffeine in the treatment of apnea in the premature infant]. Arch Fr Pediatr 47:221-224.

Mumford GK, Benowitz NL, Evans SM, Kaminski BJ, Preston KL, Sannerud CA Silverman K, and Griffiths RR (1996) Absorption rate of methylxanthines following capsules, cola and chocolate. Eur J Clin Pharmacol 51:319-325.

Muscat JE, Pittman B, Kleinman W, Lazarus P, Stellman SD, and Richie JP Jr (2008) Comparison of CYP1A2 and NAT2 phenotypes between black and white smokers. Biochem Pharmacol 76:929-937.

Nada AH (1991) Influence of caffeine on the renal effects and solubility of ketoprofene. Int J Pharmacol 70:191-193.

Nehlig A (2004) Dependence upon coffee and caffeine: an update, in Coffee, Tea, Chocolate and the Brain (Nehlig A ed) pp 133-146, CRC Press, Boca Raton, CA.

Nehlig A (2010) Is caffeine a cognitive enhancer? J Alzheimers Dis 20 (Suppl 1): S85-S94.

Nehlig A, Daval JL, Boyet S, and Vert P (1986) Comparative effects of acute and chronic administration of caffeine on local cerebral glucose utilization in the conscious rat. Eur J Pharmacol 129:93-103.

Nehlig A and Fredholm BB (2004) Caffeine effects in ischemia and seizures: paradoxical effects of long-term exposure, in Coffee, Tea, Chocolate and the Brain (Nehlig A, ed) pp 165-174, CRC Press, Boca Raton.

Nordestgaard AT and Nordestgaard BG (2016) Coffee intake, cardiovascular disease and all-cause mortality: observational and Mendelian randomization analyses in 95 000-223 000 individuals. Int J Epidemiol 45:1938-1952.

Nunes RA, Mazzotti DR, Hirotsu C, Andersen ML, Tufik S, and Bittencourt L (2017) The association between caffeine consumption and objective sleep variables is dependent on ADORA2A c.1083T $>$ C genotypes. Sleep Med 30:210-215.

Palacios N, Gao X, McCullough ML, Schwarzschild MA, Shah R, Gapstur S, and Ascherio A (2012) Caffeine and risk of Parkinson's disease in a large cohort of men and women. Mov Disord 27:1276-1282.

Palacios N, Weisskopf M, Simon K, Gao X, Schwarzschild M, and Ascherio A (2010) Polymorphisms of caffeine metabolism and estrogen receptor genes and risk of Parkinson's disease in men and women. Parkinsonism Relat Disord 16:370-375.

Panza F, Solfrizzi V, Barulli MR, Bonfiglio C, Guerra V, Osella A, Seripa D, Sabbà C, Pilotto A, and Logroscino G (2015) Coffee, tea, and caffeine consumption and prevention of late-life cognitive decline and dementia: a systematic review. J Nutr Health Aging 19:313-328.

Park GJ, Katelaris PH, Jones DB, Seow F, Le Couteur DG, and Ngu MC (2003) Validity of the 13C-caffeine breath test as a noninvasive, quantitative test of liver function. Hepatology 38:1227-1236.

Parsons WD and Neims AH (1978) Effect of smoking on caffeine clearance. Clin Pharmacol Ther 24:40-45.

Persico AM, Militerni R, Bravaccio C, Schneider C, Melmed R, Trillo S, Montecchi F, Palermo MT, Pascucci T, Puglisi-Allegra S, et al. (2000) Adenosine deaminase alleles and autistic disorder: case-control and family-based association studies. Am $J$ Med Genet 96:784-790.

Perucca E (2005) An introduction to antiepileptic drugs. Epilepsia 46 (Suppl 4): 31-37.

Ping J, Lei YY, Liu L, Wang TT, Feng YH, and Wang H (2012) Inheritable stimulatory effects of caffeine on steroidogenic acute regulatory protein expression and cortisol production in human adrenocortical cells. Chem Biol Interact 195:68-75.

Pirastu N, Kooyman M, Robino A, van der Spek A, Navarini L, Amin N, Karssen LC, Van Duijn CM, and Gasparini P (2016) Non-additive genome-wide association scan reveals a new gene associated with habitual coffee consumption. Sci Rep 6:31590.

Pollock BG, Wylie M, Stack JA, Sorisio DA, Thompson DS, Kirshner MA, Folan MM, and Condifer KA (1999) Inhibition of caffeine metabolism by estrogen replacement therapy in postmenopausal women. J Clin Pharmacol 39:936-940.

Pons G, Blais JC, Rey E, Plissonnier M, Richard MO, Carrier O, d'Athis P, Moran C, Badoual J, and Olive G (1988) Maturation of caffeine N-demethylation in infancy: a study using the ${ }^{13} \mathrm{CO} 2$ breath test. Pediatr Res 23:632-636.

Popat RA, Van Den Eeden SK, Tanner CM, Kamel F, Umbach DM, Marder K Mayeux R, Ritz B, Ross GW, Petrovitch H, et al. (2011) Coffee, ADORA2A, and CYP1A2: the caffeine connection in Parkinson's disease. Eur J Neurol 18:756-765.

Posadzki P, Watson L, and Ernst E (2013) Herb-drug interactions: an overview of systematic reviews. Br J Clin Pharmacol 75:603-618.

Qi H and Li S (2014) Dose-response meta-analysis on coffee, tea and caffeine consumption with risk of Parkinson's disease. Geriatr Gerontol Int 14:430-439.

Qi LW, Wang CZ, Du GJ, Zhang ZY, Calway T, and Yuan CS (2011) Metabolism of ginseng and its interactions with drugs. Curr Drug Metab 12:818-822.

Raaska K, Raitasuo V, Laitila J, and Neuvonen PJ (2004) Effect of caffeinecontaining versus decaffeinated coffee on serum clozapine concentrations in hospitalised patients. Basic Clin Pharmacol Toxicol 94:13-18.

Rasmussen BB, Brix TH, Kyvik KO, and Brøsen K (2002) The interindividual differences in the 3-demthylation of caffeine alias CYP1A2 is determined by both genetic and environmental factors. Pharmacogenetics 12:473-478.

Rebola N, Lujan R, Cunha RA, and Mulle C (2008) Adenosine A2A receptors are essential for long-term potentiation of NMDA-EPSCs at hippocampal mossy fiber synapses. Neuron 57:121-134. 
Rétey JV, Adam M, Honegger E, Khatami R, Luhmann UF, Jung HH, Berger W, and Landolt HP (2005) A functional genetic variation of adenosine deaminase affects the duration and intensity of deep sleep in humans. Proc Natl Acad Sci USA 102:15676-15681.

Rétey JV, Adam M, Khatami R, Luhmann UF, Jung HH, Berger W, and Landolt HP (2007) A genetic variation in the adenosine A2A receptor gene (ADORA2A) contributes to individual sensitivity to caffeine effects on sleep. Clin Pharmacol Ther 81:692-698.

Rieth N, Vibarel-Rebot N, Buisson C, Jaffré C, and Collomp K (2016) Caffeine and saliva steroids in young healthy recreationally trained women: impact of regular caffeine intake. Endocrine 52:391-394.

Rietveld EC, Broekman MM, Houben JJ, Eskes TK, and van Rossum JM (1984) Rapid onset of an increase in caffeine residence time in young women due to oral contraceptive steroids. Eur J Clin Pharmacol 26:371-373.

Ritchie K, Carrière I, de Mendonca A, Portet F, Dartigues JF, Rouaud O, BarbergerGateau P, and Ancelin ML (2007) The neuroprotective effects of caffeine: a prospective population study (the Three City Study). Neurology 69:536-545.

Rocha L, Garcia C, de Mendonça A, Gil JP, Bishop DT, and Lechner MC (1999) Nacetyltransferase (NAT2) genotype and susceptibility of sporadic Alzheimer's disease. Pharmacogenetics 9:9-15.

Rogers PJ, Hohoff C, Heatherley SV, Mullings EL, Maxfield PJ, Evershed RP, Deckert J, and Nutt DJ (2010) Association of the anxiogenic and alerting effects of caffeine with ADORA2A and ADORA1 polymorphisms and habitual level of caf feine consumption. Neuropsychopharmacology 35:1973-1983.

Roncucci R, Verry M, and Jeanniot JP (1982) Interactions between nutrition, food and drugs in man. World Rev Nutr Diet 43:140-152.

Rupp TL, Wesensten NJ, Newman R, and Balkin TJ (2013) PER3 and ADORA2A polymorphisms impact neurobehavioral performance during sleep restriction. $J$ Sleep Res 22:160-165.

Sachse C, Brockmöller J, Bauer S, and Roots I (1999) Functional significance of a C-$>$ A polymorphism in intron 1 of the cytochrome P450 CYP1A2 gene tested with caffeine. Br J Clin Pharmacol 47:445-449.

Salinero JJ, Lara B, Ruiz-Vicente D, Areces F, Puente-Torres C, Gallo-Salazar C, Pascual T, and Del Coso J (2017) CYP1A2 genotype variations do not modify the benefits and drawbacks of caffeine during exercise: a pilot study. Nutrients 9: E269.

Santos C, Lunet N, Azevedo A, de Mendonça A, Ritchie K, and Barros H (2010) Caffeine intake is associated with a lower risk of cognitive decline: a cohort study from Portugal. J Alzheimers Dis 20 (Suppl 1):S175-S185.

Santos RMM, Cotta K, and Lima DRA(2016) Evaluation of a potential association between CYP1A2 caffeine metabolism and coffee consumption in healthy volunteers. Proceedings of the $26^{\text {th }}$ ASIC Conference, Kunming, China, November 12-17, 2016, Abstract PXH 002

Saruwatari J, Nakagawa K, Shindo J, Tajiri T, Fujieda M, Yamazaki H, Kamataki T, and Ishizaki T (2002) A population phenotyping study of three drug-metabolizing enzymes in Kyushu, Japan, with use of the caffeine test. Clin Pharmacol Ther 72:200-208.

Saruwatari J, Takashima A, Yoshida K, Soraoka H, Ding TB, Uchiyashiki Y, Tsuda Y, Imamura M, Oniki K, Miyata K, et al. (2014) Effects of Seijo-bofu-to, a traditional Japanese herbal medicine containing furanocoumarin derivatives, on the drug-metabolizing enzyme activities in healthy male volunteers. Basic Clin Pharmacol Toxicol 115:360-365.

Sasaki S, Limpar M, Sata F, Kobayashi S, and Kishi R (2017) Interaction between maternal caffeine intake during pregnancy and CYP1A2 C164A polymorphism affects infant birth size in the Hokkaido study. Pediatr Res 82:19-28.

Schmider J, Brockmöller J, Arold G, Bauer S, and Roots I (1999) Simultaneous assessment of CYP3A4 and CYP1A2 activity in vivo with alprazolam and caffeine. Pharmacogenetics 9:725-734.

Scott NR, Chakraborty J, and Marks V (1986) Urinary metabolites of caffeine in pregnant women. Br J Clin Pharmacol 22:475-478

Scott NR, Stambuk D, Chakraborty J, Marks V, and Morgan MY (1988) Caffeine clearance and biotransformation in patients with chronic liver disease. Clin Sci (Lond) 74:377-384.

Sebastião AM, Assaife-Lopes N, Diógenes MJ, Vaz SH, and Ribeiro JA (2011) Modulation of brain-derived neurotrophic factor (BDNF) actions in the nervous system by adenosine $\mathrm{A}(2 \mathrm{~A})$ receptors and the role of lipid rafts. Biochim Biophys Acta 1808: $1340-1349$

Shirley KL, Hon YY, Penzak SR, Lam YW, Spratlin V, and Jann MW (2003) Correlation of cytochrome P450 (CYP) 1A2 activity using caffeine phenotyping and olanzapine disposition in healthy volunteers. Neuropsychopharmacology 28:961-966.

Shulman LM (2002) Is there a connection between estrogen and Parkinson's disease? Parkinsonism Relat Disord 8:289-295.

Signorello LB, Nordmark A, Granath F, Blot WJ, McLaughlin JK, Annerén G, Lundgren S, Ekbom A, Rane A, and Cnattingius S (2001) Caffeine metabolism and the risk of spontaneous abortion of normal karyotype fetuses. Obstet Gynecol $\mathbf{9 8}$ : $1059-1066$.

Silva CG, Métin C, Fazeli W, Machado NJ, Darmopil S, Launay PS, Ghestem A, Nesa MP, Bassot E, Szabó E, et al. (2013) Adenosine receptor antagonists including caffeine alter fetal brain development in mice. Sci Transl Med 5:197ra104.

Simon DK, Wu C, Tilley BC, Lohmann K, Klein C, Payami H, Wills AM, Aminoff MJ, Bainbridge J, Dewey R, et al. (2017) Caffeine, creatine, GRIN2A and Parkinson's disease progression. J Neurol Sci 375:355-359.

Smith A (2002) Effects of caffeine on human behavior. Food Chem Toxicol 40: $1243-1255$.

Snel J (1993) Coffee and caffeine: sleep and wakefulness, in Caffeine, Coffee and Health (Garattini S ed) pp 255-290, Raven Press, New York.

Somani SM, Khanna NN, and Bada HS (1980) Caffeine and theophylline: serum/CSF correlation in premature infants. J Pediatr 96:1091-1093.

Soto J, Sacristan JA, and Alsar MJ (1994) Diltiazem treatment impairs theophylline elimination in patients with bronchospastic airway disease. Ther Drug Monit 16:49-52.

Sulem P, Gudbjartsson DF, Geller F, Prokopenko I, Feenstra B, Aben KK, Franke B, den Heijer M, Kovacs P, Stumvoll M, et al. (2011) Sequence variants at CYP1A1-
CYP1A2 and AHR associate with coffee consumption. Hum Mol Genet 20: 2071-2077.

Svenningsson P, Nomikos GG, and Fredholm BB (1999) The stimulatory action and the development of tolerance to caffeine is associated with alterations in gene expression in specific brain regions. J Neurosci 19:4011-4022.

Swan GE, Carmelli D, and Cardon LR (1996) The consumption of tobacco, alcohol, and coffee in Caucasian male twins: a multivariate genetic analysis. $J$ Subst Abuse 8:19-31.

Swanson JA, Lee JW, Hopp JW, and Berk LS (1997) The impact of caffeine use on tobacco cessation and withdrawal. Addict Behav 22:55-68.

Tan EK, Lu ZY, Fook-Chong SM, Tan E, Shen H, Chua E, Yih Y, Teo YY, and Zhao Y (2006) Exploring an interaction of adenosine A2A receptor variability with coffee and tea intake in Parkinson's disease. Am J Med Genet B Neuropsychiatr Genet 141B:634-636

Tanaka H, Nakazawa K, Arima M, and Iwasaki S (1984) Caffeine and its dimethylxanthines and fetal cerebral development in rat. Brain Dev 6:355-361.

Tang J, Sun J, Zhang Y, Li L, Cui F, and He Z (2007) Herb-drug interactions: effect of Ginkgo biloba extract on the pharmacokinetics of theophylline in rats. Food Chem Toxicol 45:2441-2445.

Tang W and Eisenbrand G (2011) Handbook of Chinese Medicinal Plants, Chemistry, Pharmacology and Toxicology. Wiley VCH Verlag, Weinheim, Germany.

Tang-Liu DD, Williams RL, and Riegelman S (1983) Disposition of caffeine and its metabolites in man. $J$ Pharmacol Exp Ther 224:180-185.

Tantcheva-Poór I, Zaigler M, Rietbrock S, and Fuhr U (1999) Estimation of cytochrome P-450 CYP1A2 activity in 863 healthy Caucasians using a saliva-based caffeine test. Pharmacogenetics 9:131-144.

Traganos F, Kaminska-Eddy B, and Darzynkiewicz Z (1991) Caffeine reverses the cytotoxic and cell kinetic effects of Novantrone (mitoxantrone). Cell Prolif 24: $305-319$

Trang JM, Blanchard J, Conrad KA, and Harrison GG (1985) Relationship between total body clearance of caffeine and urine flow rate in elderly men. Biopharm Drug Dispos 6:51-56.

Tsai HH, Lin HW, Simon Pickard A, Tsai HY, and Mahady GB (2012) Evaluation of documented drug interactions and contraindications associated with herbs and dietary supplements: a systematic literature review. Int $J$ Clin Pract 66 1056-1078.

Tsai TH, Chang CH, and Lin LC (2005) Effects of Evodia rutaecarpa and rutaecarpine on the pharmacokinetics of caffeine in rats. Planta Med 71:640-645.

Tsutsumi K, Kotegawa T, Matsuki S, Tanaka Y, Ishii Y, Kodama Y, Kuranari M, Miyakawa I, and Nakano S (2001) The effect of pregnancy on cytochrome P4501A2, xanthine oxidase, and N-acetyltransferase activities in humans. Clin Pharmacol Ther 70:121-125.

Turmen T, Louridas TA, and Aranda JV (1979) Relationship of plasma and CSF concentrations of caffeine in neonates with apnea. J Pediatr 95:644-646.

Urry E, Jetter A, and Landolt HP (2016) Assessment of CYP1A2 enzyme activity in relation to type-2 diabetes and habitual caffeine intake. Nutr Metab (Lond) 13:66

Vanattou-Saïfoudine N, McNamara R, and Harkin A (2012) Caffeine provokes adverse interactions with 3,4-methylenedioxymethamphetamine (MDMA, 'ecstasy') and related psychostimulants: mechanisms and mediators. Br J Pharmacol 167:946-959.

Vaz J, Kulkarni C, David J, and Joseph T (1998) Influence of caffeine on pharmacokinetic profile of sodium valproate and carbamazepine in normal human volunteers. Indian J Exp Biol 36:112-114.

Vistisen K, Loft S, and Poulsen HE (1991) Cytochrome P450 IA2 activity in man measured by caffeine metabolism: effect of smoking, broccoli and exercise. Adv Exp Med Biol 283:407-411.

Vistisen K, Poulsen HE, and Loft S (1992) Foreign compound metabolism capacity in man measured from metabolites of dietary caffeine. Carcinogenesis 13:1561-1568.

Walton K, Dorne JL, and Renwick AG (2001) Uncertainty factors for chemical risk assessment: interspecies differences in the in vivo pharmacokinetics and metabolism of human CYP1A2 substrates. Food Chem Toxicol 39:667-680.

Walzer M, Bekersky I, Blum RA, and Tolbert D (2012) Pharmacokinetic drug in teractions between clobazam and drugs metabolized by cytochrome P450 isoenzymes. Pharmacotherapy 32:340-353.

Watson J, Deary I, and Kerr D (2002) Central and peripheral effects of sustained caffeine use: tolerance is incomplete. Br J Clin Pharmacol 54:400-406.

Wedick NM, Mantzoros CS, Ding EL, Brennan AM, Rosner B, Rimm EB, Hu FB, and van Dam RM (2012) The effects of caffeinated and decaffeinated coffee on sex hormone-binding globulin and endogenous sex hormone levels: a randomized controlled trial. Nutr $J$ 11:86.

Welfare MR, Bassendine MF, and Daly AK (2000) The effect of NAT2 genotype and gender on the metabolism of caffeine in nonsmoking subjects. $\mathrm{Br}$ J Clin Pharmacol 49:240-243.

Whitfield K, Rambaldi A, Wetterslev J, and Gluud C (2009) Pentoxifylline for alcoholic hepatitis. Cochrane Database Syst Rev 4:CD007339.

Whitten DL, Myers SP, Hawrelak JA, and Wohlmuth H (2006) The effect of St John's wort extracts on CYP3A: a systematic review of prospective clinical trials. $\mathrm{Br} \mathrm{J} \mathrm{Clin}$ Pharmacol 62:512-526.

Wlaź P, Roliński Z, Kleinrok Z, and Czuczwar SJ (1992) Anticonvulsant activity of carbamazepine and diphenylhydantoin against maximal electroshock in mice chronically treated with aminophylline. J Neural Transm (Vienna) 89:41-48.

Xu H, Rajesan R, Harper P, Kim RB, Lonnerdal B, Yang M, Uematsu S, Hutson J, Watson-MacDonell J, and Ito S (2005) Induction of cytochrome P450 1A by cow milk-based formula: a comparative study between human milk and formula. $\mathrm{Br} J$ Pharmacol 146:296-305.

Xu K, Xu Y, Brown-Jermyn D, Chen JF, Ascherio A, Dluzen DE, and Schwarzschild MA (2006) Estrogen prevents neuroprotection by caffeine in the mouse 1-methyl-4-phenyl-1,2,3,6-tetrahydropyridine model of Parkinson's disease. J Neurosci 26:535-541.

Yamada-Fowler N, Fredrikson M, and Söderkvist P (2014) Caffeine interaction with glutamate receptor gene GRIN2A: Parkinson's disease in Swedish population. PLoS One 9:e99294. 
Yamada-Fowler N and Söderkvist P (2015) Coffee, genetic variants, and Parkinson's Disease: gene-environment interactions. J Caffeine Res 5:3-10.

Yamazaki T, Desai A, Goldwater R, Han D, Howieson C, Akhtar S, Kowalski D Lademacher C, Pearlman H, Rammelsberg D, et al. (2016) Pharmacokinetic effects of isavuconazole coadministration with the cytochrome P450 enzyme substrates bupropion, repaglinide, caffeine, dextromethorphan, and methadone in healthy subjects. Clin Pharmacol Drug Dev 6:54-65.

Yamazaki T, Desai A, Goldwater R, Han D, Howieson C, Akhtar S, Kowalski D, Lademacher C, Pearlman H, Rammelsberg D, et al. (2017) Pharmacokinetic effects of isavuconazole coadministration with the cytochrome P450 enzyme substrates bupropion, repaglinide, caffeine, dextromethorphan, and methadone in healthy subjects. Clin Pharmacol Drug Dev 6:54-65.

Yang A, Palmer AA, and de Wit H (2010) Genetics of caffeine consumption and responses to caffeine. Psychopharmacology (Berl) 211:245-257.
Yu T, Campbell SC, Stockmann C, Tak C, Schoen K, Clark EA, Varner MW, Spigarelli MG, and Sherwin CM (2016) Pregnancy-induced changes in the pharmacokinetics of caffeine and its metabolites. J Clin Pharmacol 56:590-596.

Zandvliet AS, Huitema AD, de Jonge ME, den Hoed R, Sparidans RW, Hendriks VM, van den Brink W, van Ree JM, and Beijnen JH (2005) Population pharmacokinetics of caffeine and its metabolites theobromine, paraxanthine and theophylline after inhalation in combination with diacetylmorphine. Basic Clin Pharmacol Toxicol 96:71-79.

Zuchinali P, Ribeiro PA, Pimentel M, da Rosa PR, Zimerman LI, and Rohde LE (2016) Effect of caffeine on ventricular arrhythmia: a systematic review and metaanalysis of experimental and clinical studies. Europace 18:257-266.

Zuchora B, Wielosz M, and Urbańska EM (2005) Adenosine A1 receptors and the anticonvulsant potential of drugs effective in the model of 3-nitropropionic acidinduced seizures in mice. Eur Neuropsychopharmacol 15:85-93. 